\title{
EL DESARROLLO DE LA TRASHUMANCIA Y LOS ORÍGENES MEDIEVALES DE LA CUADRILLA MESTEÑA SORIANA
}

por

\section{Máximo Diago Hernando}

Instituto de Historia. CSIC. Madrid.

RESUMEN: Contribución a la bistoria de la trashumancia y de la Mesta que se centra en el espacio abarcado por uno de los cuatro partidos mesteños, el de Soria, al que se reconocían ciertos derechos de precedencia dentro de esta institución. El autor demuestra que la ganadería trasbumante se desarrolló tempranamente en este espacio, en particular en su sector serrano, tanto en los territorios de señorio, entre los que destaca la Tierra de Yanguas, como en los de realengo, de los que el principal era la Tierra de Soria. Hasta el siglo XV se trató, no obstante, de una actividad orientada prioritariamente a garantizar la subsistencia de familias campesinas asentadas en espacios poco aptos para la agricultura. Pero a partir de ese siglo, por el despegue de la demanda de lanas en el mercado internacional, adoptó una orientación decididamente especulativa, y propició la movilidad social, y el desarrollo de un grupo de familias de grandes propietarios ganaderos, que concentraron en sus manos la mayor parte de la cabaña hasta comienzos del siglo XIX.

Palabras clave: Mesta. Castilla. Soria. Trashumancia. Comercio de lanas. Baja Edad Media.

ABSTRACT: This article is a contribution to the bistory of the transhumance and the Mesta, focusing on the region comprised by the one of the Mesta's four districts: Soria, a district enjoying certain rights of precedence in this institution. The author shows that the activity of transhumant ranching developed early in this region, in particular in its mountainous sector, not only in seigneurial territories like Yanguas, but also in royal territories like Soria. Until the fifteenth century, transhumance was basically an activity designed to ensure the subsistence of peasant families living in territories unsuitable for agriculture. But from the beginning of the fifteenth century, as a consequence of the sudden increase in the international demand for wool, it increasingly engaged in speculation, stimulating both social 
mobility and the development of a group of big sheep-owning families who largely monopolized transhumant livestock until the beginning of the nineteenth century.

KeY WORDS: Mesta. Castile. Soria. Transhumance. Wool trade. Late Middle Ages.

\section{EL DESARROLLO DE LA TRASHUMANCIA Y LOS ORÍGENES MEDIEVALES DE LA CUADRILLA MESTEÑA SORIANA}

La reconstrucción del proceso de desarrollo de la ganadería trashumante de largo recorrido en la Corona de Castilla en los siglos XIII y XIV representa una tarea plagada de dificultades, debido a la extrema escasez de fuentes documentales disponibles para llevarla a cabo. Y algo parecido se puede decir de la reconstrucción de la historia institucional de la Mesta en este mismo período. Muchas cuestiones de interés central para el conocimiento y comprensión de ambos procesos probablemente no llegarán a ser nunca satisfactoriamente clarificadas, pues las expectativas de encontrar fuentes de información que contribuyan a paliar nuestra actual ignorancia son escasas. Pero, a pesar de ello, un mejor aprovechamiento de las informaciones aportadas por la documentación disponible, junto a la búsqueda de nuevos datos en fuentes todavía inexploradas, puede contribuir a hacer avanzar nuestros conocimientos sobre esta oscura parcela de la historia económica castellana, dado que las investigaciones que se han dedicado hasta ahora a su análisis son insuficientes.

Es por ello que nos hemos propuesto efectuar una primera contribución a esta difícil y compleja empresa, centrando nuestra atención en el análisis particularizado de un ámbito geográfico restringido, uno de los muchos que estuvieron involucrados en el doble proceso de desarrollo de la ganadería trashumante y de la Mesta en la Corona de Castilla, para así poder aprovechar de forma más intensiva la documentación disponible, y reflexionar más en profundidad sobre las posibilidades interpretativas que ésta ofrece. $Y$ a este efecto hemos seleccionado como objeto de estudio el ámbito geográfico abarcado por el partido mesteño de Soria, uno de los cuatro partidos serranos en que se agruparon los señores de ganados miembros de la Mesta durante los más de cinco siglos de existencia de esta institución.

La relevancia de este partido para un estudio dedicado a los orígenes y evolución de la Mesta en sus primeras fases es notable por muchas razones, que guardan relación con el hecho de que en el seno de esta institución se le reconoció una posición preeminente frente a los otros tres en cuestiones de protocolo y precedencia, tan del gusto de las sociedades del Antiguo Régimen. Y dicha posición se ha explicado como consecuencia de que los sorianos habían sido pioneros en la práctica de la trashumancia de largo recorrido en Castilla, y habían asumido por ello un papel protagonista en el proceso de creación de la Mesta.

Hispania, LXIV/3, núm. 218 (2004) 1045-1078 
En efecto, la posición preeminente reconocida al partido soriano en el seno de la Mesta se traducía en primer lugar en el derecho que asistía a uno de sus miembros a tomar asiento en las asambleas de la institución a la derecha de la persona que las presidía, que a partir del año 1500 era un presidente designado por los reyes entre los miembros del Consejo de Castilla. Y otro importante privilegio en materia de protocolo del que disfrutaban los ganaderos del partido mesteño soriano les reconocía el derecho a permanecer en la sala donde se celebraban las asambleas generales, en compañía del presidente de la Mesta, cada vez que se debían reunir los partidos por separado para proceder a elecciones de oficiales o tomar otro tipo de acuerdos, mientras que los ganaderos adscritos a los otros tres partidos debían abandonar entonces dicha sala y proceder a reunirse fuera de ella, cada uno en un lugar diferente.

Esta posición de preferencia reconocida a los señores de ganados sorianos en la Mesta era consecuencia según Manuel del Río, ganadero de la aldea soriana de Castilfrío de la Sierra que escribió un pequeño tratado a comienzos del siglo XIX, del hecho de que la sierra de Soria había sido el origen de la ganadería trashumante, que después había sido transferida a las sierras de Cuenca, Segovia y León. Pues, según este autor, los sorianos habían sido los primeros que poblaron con sus ganados las dehesas de Extremadura, y eran mucho más antiguos en el pastoreo que los montañeses, que les debían precisamente a ellos

\footnotetext{
«la colocación de los ganados trashumantes en su país, el arreglo de los puertos, el método y orden que gobierna las cabañas leonesas»1.
}

Resultaría de todo punto improcedente tomar al pie de la letra estas aseveraciones, pues incluyen evidentes exageraciones y ni siquiera se basan en pruebas seguras y contrastables, sino en la simple asunción, por lo demás interesada, de una tradición oral. Pero no podemos excluir tampoco que en ellas subyazca un fondo de verdad, sobre todo en lo que se refiere al más temprano desarrollo de la actividad ganadera trashumante en las sierras sorianas con respecto a otras regiones que durante la Edad Moderna llegaron a consolidarse como los principales ámbitos de acogida de ganado trashumante en los meses de verano, en concreto las montañas de León. En efecto, el hecho de que, en el orden de prelación de las asambleas mesteñas, el partido de Soria ocupase siempre el primer lugar y el de León el último, entendemos que no obedeció a simple arbitrariedad, sino que guardó estrecha relación con el papel que los ganaderos que aprovechaban los pastos de las sierras sorianas y leonesas desempeñaron en las primeras etapas de funcionamiento de la Mesta.

En un estudio comparativo de la estructura interna de estos dos partidos uno de los hechos que más llama la atención es que, mientras que en el de Soria estuvieron integrados exclusivamente señores de ganados avecindados en lugares de las sierras sorianas, por el contrario en el partido de León la inmensa mayoría de

1 Río, Manuel del: Vida pastoril. Madrid, Imprenta del Repullés, 1828, pp. 2, 11 y 12. 
sus miembros fueron durante la Edad Moderna vecinos de lugares de las serranías ibéricas de las actuales provincias de Rioja y Burgos. Y, además, un simple repaso a las actas de las asambleas celebradas en las primeras décadas del siglo XVI, las primeras de las que se conserva registro documental, demuestra que con frecuencia entonces fueron ganaderos originarios de los partidos de Soria y de Segovia los que accidentalmente asumieron la representación del partido de León en dichas asambleas, por no encontrarse presentes en ellas suficientes y cualificados propietarios procedentes de las comarcas adscritas a dicho partido. De momento nos resulta difícil ofrecer una explicación satisfactoria para tan extraño fenómeno, pero lo que sí parece fuera de duda es que el partido de León fue el más inmaduro de todos los partidos mesteños, y que la escasa presencia de leoneses en su seno lo convirtió en un partido atípico. Y, en efecto, atípica fue también la situación de las montañas leonesas en relación con el resto de comarcas serranas que acogieron en verano rebaños ovinos trashumantes durante los siglos medievales y modernos, debido a que sus pastos, que eran reputados como los de mayor calidad del reino, fueron aprovechados en su mayor parte por ganados pertenecientes a propietarios forasteros, que tenían fijada su residencia en ciudades alejadas cientos de kilómetros de dichas sierras.

Teniendo en cuenta estas circunstancias, resulta justificado, por tanto, sentirse tentado a coincidir con Manuel del Río en que los sorianos precedieron a los leoneses en la práctica de la trashumancia, y por consiguiente también en la puesta en funcionamiento de la institución mesteña, y por ello consiguieron consolidar en el seno de ésta una posición de preeminencia, ratificada por el protocolo que regulaba el orden de precedencia. Más controvertido resulta, sin embargo, determinar si los ganaderos sorianos fueron también más precoces que segovianos y conquenses en la empresa de llevar sus rebaños a los «estremos» durante los inviernos, y por este motivo éstos les cedieron el primer puesto en sus asambleas cuando todos decidieron unir sus esfuerzos, bajo la tutela de la monarquía, para conseguir una mejor defensa de sus intereses en las comarcas de pastos de invernadero y en los territorios que debían atravesar durante sus desplazamientos. No vamos a entrar por ello en el tratamiento de esta cuestión, que probablemente nunca podrá llegar a ser resuelta de forma satisfactoria, por incapacidad de los investigadores de reconstruir en sus detalles las primeras fases de funcionamiento institucional de la Mesta. Pero, al menos, para contribuir al mejor conocimiento de estas primeras fases, trataremos de determinar cuál pudo ser la contribución de los ganaderos del partido soriano al proceso.

\section{INDICIOS DE LA TEMPRANA PARTICIPACIÓN DE LOS SORIANOS EN LA TRAS- HUMANCIA}

La tesis defendida por Manuel del Río de que los vecinos de las sierras de Soria fueron los primeros en practicar la ganadería trashumante a gran escala, sentando así las bases de una actividad económica y un modo de vida que des- 
pués serían adoptados por los habitantes de otros ámbitos serranos del reino de Castilla, apenas resulta posible corroborarla con pruebas documentales consistentes, pues las escasas fuentes documentales disponibles para la reconstrucción de la historia soriana en los siglos XIII y XIV son muy parcas en noticias referentes a la práctica del pastoreo trashumante. Alguna, sin embargo, existe, y se puede considerar suficientemente ilustrativa.

En concreto cabría destacar un documento del año 1306 que nos informa del compromiso firmado ese año para zanjar sus diferencias entre Fernán Méndez, comendador de Almadén, de la Orden de Calatrava, y Gonzalo Fernández, en nombre de Garcí López de Padilla, maestre de Calatrava, de una parte, y de otra Pascual Pérez, vecino de Viniegra, y Martín Gil, vecino de San Pedro de Yanguas, en nombre del concejo de La Mesta ${ }^{2}$. Y consideramos importante este documento porque en primer lugar nos confirma que individuos avecindados en las comarcas serranas situadas al norte de la Tierra de Soria estaban interesados en el aprovechamiento de las dehesas de invernadero del Campo de Calatrava, y en segundo lugar que desempeñaban un papel de cierta relevancia en el seno de la institución mesteña, hasta el punto de ser designados algunos de ellos como procuradores para resolver litigios en representación suya.

El papel de primera fila que la región soriana ocupó en la Mesta durante la primera mitad del siglo XIV es por otra parte también sugerido por algunos otros documentos que dan fe de cómo fue entonces el escenario preferido para las asambleas que esta institución celebraba cada año en torno a la fiesta de Santiago, en las que se procedía a la designación de sus procuradores, que desempeñaban el cargo por el período de un año. Así, sabemos que la del año 1326 tuvo lugar en la propia ciudad de Soria ${ }^{3}$, y en la cercana villa de Berlanga de Duero se celebraron las de $1344^{4}$ y $1357^{5}$.

2 Real Academia de la Historia, Salazar y Castro, M-70, fols. 1-5, escritura otorgada el 7 de mayo de 1306, s.l.

3 Ser QuiJano, Gregorio del: Documentación Medieval del Archivo Municipal de San Bartolomé de Pinares (Ávila), Avila, 1987. Docs. 5 y.6, Soria, 30-VII-1326. Nombramientos por el concejo general de la Mesta como sus procuradores de Adán Pérez y Gil de Torre. En ambos documentos se utiliza el siguiente encabezamiento: «Nos el conçeio de la Mesta de los pastores que entramos a los estremos, que nos ayuntamos en Soria en la mesta de Santiago en mesta general».

4 Vid. carta de nombramiento como procuradores de la Mesta de Miguel Domingo y Juan Pérez de Ríofrío, fechada en Berlanga, 29-VII-1344 en Domingo PALACIO,-T.: Documentos del Archivo General de la Villa de Madrid, I, Madrid, 1888. pp. 257-70. Aparece inserta en un documento fechado en Madrid, 15-VI-1345. La carta se inicia con el siguiente encabezamiento: «Sepan quantos esta carta de personería vieren como nos el concejo de la mesta de los pastores que entramos a los estremos e nos ayuntamos en Berlanga en la mesta de Sant Yague, mesta general...»

5 Vid. carta de nombramiento de Juan Ortiz de Segovia como procurador por «nos el concejo de la Mesta de los pastores estando ayuntados en Berlanga en nuestra Mesta general que fazemos en el día de Santiago de julio». La carta está fechada, no obstante, en Berlanga 1-VII-1357. En Domingo PALACIO, T.: op. cit. pp. 345-366. Está inserta en documento fechado en Madrid, 18-XII-1357. 
Y, en esta misma línea, también hay que destacar la noticia proporcionada por un documento del año 1322, que demuestra que por aquellas fechas la trashumancia de largo recorrido era habitualmente practicada en la región soriana no sólo por los vecinos de las comarcas serranas, sino también por los de algunos lugares de tierras llanas. Se trata en concreto de una carta que en enero de aquel año dirigió el rey de Aragón Jaime II a Don Juan Manuel, en la cual denunciaba que el año anterior, cuando iban a «Estremo» las ovejas de Tierra de Almazán y de Tierra de Berlanga, dos caballeros vasallos de este poderoso noble castellano, de nombre Pedro Martínez y Alfonso Pérez, se habían apoderado de una partida de aquellas ovejas, que eran propiedad de Ruy Pérez, alguacil de la infanta María, hija del monarca aragonés y viuda del infante castellano Don Pedro, y de otros vasallos de ésta, vecinos de los referidos lugares de Berlanga y Almazán, que habían formado parte del patrimonio señorial del referido infante ${ }^{6}$.

A partir de tan escasas y parcas noticias resulta muy difícil hacer una valoración rigurosa sobre el estado de la ganadería trashumante en la región soriana durante el siglo XIV, y sobre el papel que los propietarios ganaderos de dicha región desempeñaron entonces en la institución mesteña. De hecho no nos ha resultado posible identificar con un mínimo de precisión a ninguno de dichos propietarios, y por consiguiente tampoco hemos podido determinar en qué grado tendieron a acaparar los principales oficios mesteños, como, por ejemplo, el de procurador, encargado de representar los intereses de los ganaderos damnificados ante los tribunales de los alcaldes entregadores? ${ }^{7}$ Pero, a pesar de todo, dichas noticias resultan suficientes para confirmarnos en la impresión de que la práctica de la trashumancia estaba plenamente consolidada entonces en toda la región soriana, tanto en su sector serrano como en las tierras llanas que se extendían al sur del mismo, más aptas en principio para el cultivo del cereal y la cría de ganado estante, asociada al mismo. Determinar, no obstante, el grado de desarrollo de esta actividad económica, y de los peculiares estilos de vida a ella asociados, en unas y otras comarcas resulta de todo

6 ACA (=Archivo Corona de Aragón), C (=Cancillería), reg. 172-279v, Tortosa, 25-I-1322. Sobre la pertenencia de Almazán y Berlanga al señorío del infante Pedro vid. Diago Hernando, Máximo: "Vicisitudes de un gran estado señorial en la frontera de Castilla con Aragón durante la primera mitad del siglo XIV: Los señoríos sorianos del infante Don Pedro", Anuario de Estudios Medievales (En prensa).

7 Conocemos los nombres de los procuradores que fueron designados en las asambleas de Santiago de los años 1326, 1344 y 1357, que fueron cinco en total, ya que en esta última sólo se eligió uno, en lugar de dos. De todos ellos sólo resulta posible determinar la procedencia en el caso de uno, Juan Pérez de Ríofrío, elegido en 1344, que era vecino de esta aldea de la Tierra de Sepúlveda. Por su parte el único procurador elegido en 1357, Juan Ortiz de Segovia, es muy probable que fuese de origen segoviano. En fechas bastante más tardías resulta posible identificar a un procurador procedente del ámbito serrano de la actual provincia de Burgos, Pascual García, vecino de Pineda de la Sierra, quien lo era en 1391. Vid. PEÑa PÉREZ, F. J.: Documentación del monasterio de Las Huelgas de Burgos (1380-1400), Burgos, 1991, doc. 411, Villasur de Herreros, 5-I-1391.

Hispania, LXIV/3, núm. 218 (2004) 1045-1078 
punto imposible, aunque la lógica nos invita a presumir que debió ser sensiblemente mayor en las serranas, en primer lugar porque las condiciones edafológicas y climáticas lo propiciaban, y en segundo lugar porque, en momentos posteriores, la mayor parte de los pastores y mayorales que atendieron las explotaciones ganaderas trashumantes sorianas, e incluso las de propietarios de otras regiones, fueron vecinos de aldeas ubicadas en estas comarcas. Y, desde nuestro punto de vista, este fenómeno fue en gran medida consecuencia del hecho de que los habitantes de dichas comarcas habían acumulado a lo largo de muchas generaciones una valiosa experiencia en la gestión de explotaciones ganaderas trashumantes, porque desde fechas muy tempranas se habían visto forzados a poner en funcionamiento este tipo de explotaciones, en muy pequeña escala, para así contribuir al sostenimiento de sus familias que, de otra forma, no les era garantizado por una tierra poco propicia para el cultivo del cereal, y en la que tampoco se podían mantener muchos ganados en invierno por impedirlo las rigurosas heladas y las frecuentes y copiosas nevadas.

$\mathrm{Y}$, de hecho, cuando las informaciones aportadas por la documentación comienzan a resultar más abundantes a partir del siglo XV, se confirma esta impresión, pues un elevado porcentaje de los ganaderos que resultan identificables en este período estaban avecindados en lugares de estas comarcas serranas, mientras que por el contrario los propietarios avecindados en lugares dé tierras llanas apenas hacen acto de presencia en los documentos de esta época.

\section{El DeSARRollo de la trashumanCia en la TierRa DE SORIA Y EN LA TIERRA DE YANGUAS DURANTE EL SIGLO XV. ANÁLISIS COMPARATIVO}

La fuente documental que aporta mayor cantidad de noticias para la identificación de los ganaderos trashumantes sorianos en la primera mitad del siglo $\mathrm{XV}$ es una colección de cuadernos conservados en la sección Osuna del Archivo de la Nobleza de Toledo, en los que se registran los pagos del impuesto del peaje efectuados por los ganaderos trashumantes a su paso por el puente de Capilla a los condes de Plasencia, señores de esta villa extremeña, en diversos ejercicios, que van desde 1428 hasta 1461, los cuales han sido minuciosamente analizados por la profesora francesa Marie Claude Gerbet ${ }^{8}$. No todos los ganaderos que aparecen registrados en dichos cuadernos fueron sorianos, aunque sí un elevado porcentaje de los mismos ${ }^{9}$. Y entre estos últimos el predominio de los que estaban avecindados en lugares de las comarcas serranas es aplastante.

\footnotetext{
8 Gerbet, M.C.:"Les serranos et le pont de Capilla au XVè. siècle: la provenance des troupeaux trashumants. La question des droits à acquitter au seigneur local», Journal of Medieval History, 17 (1991), pp. 353-386. Analiza cuadernos de cuentas de la recaudación del peaje del puente de Capilla correspondientes a los ejercicios 1428-9, 1451-2, 1452-3, 1453-4 y 1460-1.

9 Conviene advertir, no obstante, que M.C. Gerbet minusvalora la importancia relativa de los ganaderos de otras comarcas al proponer una identificación de topónimos que en ocasiones conside-
} 
Considerando las condiciones de precariedad de fuentes de información en que se ve forzado a trabajar el investigador de la historia mesteña en los siglos medievales, el contar con documentos de este tipo representa todo un golpe de fortuna. Pero tampoco se debe perder de vista que su utilidad para extraer conclusiones de carácter general sigue siendo muy limitada, pues las informaciones que proporcionan poseen un marcado carácter puntual, y sobre todo parcial, ya que sólo una fracción del conjunto de ganados sorianos que aprovechaban los pastos de invernadero de las comarcas meridionales del reino de Castilla atravesaban en sus desplazamientos el puente de Capilla, y pagaban por consiguiente peaje a los condes de Plasencia. Así, por poner un solo ejemplo, en las primeras décadas del siglo XV está constatada la presencia de ganaderos trashumantes sorianos, procedentes probablemente de San Pedro Manrique, incluso en el reino de Sevilla ${ }^{10}$.

En cualquier caso del análisis de estos cuadernos puede extraerse la segura conclusión de que durante la primera mitad del siglo XV una parte importante de los ganaderos de origen soriano que llevaron a pastar sus rebaños a las dehesas de invernadero de la actual provincia de Badajoz, y probablemente también del norte de Córdoba, estaban avecindados en la villa serrana de Yanguas o en aldeas de su Tierra. Fueron muchos, en efecto, los rebaños que se registraron a nombre de vecinos de estos lugares, las cuales en algún ejercicio llegaron a sumar más de 58.000 cabezas, aunque hubo grandes oscilaciones en el número de ganados de unos ejercicios a otros, situándose el mínimo en el ejercicio $1451-2$, con 12 rebaños, que sumaron 15.872 cabezas $^{11}$. Los dueños de algu-

ramos dudosa, o incluso errónea. El caso más significativo se refiere a un lugar que ella identifica como Poyales, pequeña aldea enclavada en la actual provincia de la Rioja, muy cerca de Enciso, pues, habiendo consultado la fuente original, creemos que la lectura más correcta es Poyatos, lugar de la Tierra de Cuenca bien conocido por la dedicación de sus vecinos a la actividad ganadera trashumante. Dado que los rebaños que ella atribuye a Poyales son muchos, y en algún caso con gran número de cabezas, si rechazamos esta identificación y optamos por Poyatos la presencia relativa de ganaderos conquenses quedaría considerablemente incrementada.

10 Proporciona la noticia CARMONa RuIZ, $\mathrm{M}^{2}$. Antonia: La ganadería en el reino de Sevilla durante la Baja Edad Media, Diputación de Sevilla, 1998, p. 381. Refiere esta autora que en 1410 Domingo Fernández y Pedro García, pastores sorianos, vasallos del adelantado Pedro Manrique, solicitaron al concejo de Sevilla cañadas para pasar a la dehesa del Caño, en Fregenal de la Sierra, perteneciente a los propios de Sevilla. Presumimos que debían ser vecinos de San Pedro Manrique, o de alguna aldea de su Tierra, por ser éste el principal señorío del adelantado en la región soriana.

11 Según los datos proporcionados por M.C. Gerbet, en 1428-9 pasaron 27 rebaños registrados a nombre de vecinos de Yanguas y su Tierra, que sumaron 58.087 cabezas, lo que representaba el $29 \%$ del total de cabezas que pagaron peaje y el 30\% de los rebaños. En el ejercicio 1451-2 fueron sólo12 rebaños que sumaron 15.872 cabezas. En 1452-3 29 rebaños (46.579 cabezas). En 1453-4 28 rebaños (44.327 cabezas). En 1454-5 28 rebaños (39.348 cabezas). Y en 1460-1 28 rebaños ( 50.930 cabezas). A título comparativo sirva recordar que en 1560, según la averiguación del licenciado Lorca, en el conjunto de villa y Tierra de Yanguas había 57.320 cabezas de ganado menudo, la mayoría ovejuno, de las cuales 15.688 pertenecían a vecinos de la villa y 41.632 a vecinos de la Tierra. Vid. Moreno Ramírez de Arellano, Miguel A.: Señorío de Cameros y Condado de Aguilar. 
nos de estos rebaños, en caso de que todas las cabezas integradas en ellos fuesen de su propiedad, pueden ser calificados incluso como auténticos grandes propietarios, pues, por ejemplo, en el ejercicio $1428-9$ se registraron a nombre de un yangüés nada menos que 10.886 cabezas, y a nombre de otro 5.183 , y en los siguientes ejercicios se siguieron registrando cabañas de en torno a las 5.000 cabezas a nombre de vecinos de Yanguas ${ }^{12}$.

La utilización de las cifras y los nombres contenidos en los cuadernos de cobro del peaje de Capilla para la realización de estimaciones cuantitativas sobre la distribución de la propiedad del ganado trashumante en las comarcas serranas sorianas la consideramos, no obstante, más que cuestionable. Ello se debe en primer lugar a que es probable que muchos de los rebaños registrados estuviesen constituidos por la agregación de los de diversos propietarios. Y, por otra parte, tampoco consideramos suficientemente demostrado que los nombres consignados en los registros fuesen siempre los de los propietarios, y no los de los mayorales que los regentaban. Así, nos parece muy sospechoso que en más de una ocasión aparezcan rebaños de más de 6.000 cabezas registrados a nombre de vecinos de lugares como Molinos, aldea de la Tierra de Soria que bien puede ser Molinos de Duero o bien Molinos de Razón, puesto que en ninguno de estos dos lugares se consolidaron en el transcurso de los siglos XV y XVI familias de grandes propietarios ganaderos, mientras que por el contrario fueron muchos los individuos allí avecindados que sirvieron como pastores a grandes propietarios vecinos de la ciudad de Soria o de otras aldeas de su Tierra ${ }^{13}$.

No vamos a entrar, sin embargo, a examinar a fondo esta cuestión, pues sería preciso llevar a cabo un análisis más detallado de todos los datos contenidos en los cuadernos, que por el momento no hemos podido acometer. Por el contrario, dejando a un lado el problema de la distribución de la propiedad del ganado trashumante y de la procedencia geográfica de los grandes propietarios, quere-

Cuatro siglos de régimen señorial en La Rioja (1366-1733), Logroño, 1992, p. 130. Por su parte a mediados del siglo XVIII, según el Catastro del Marqués de la Ensenada, había en Yanguas y su Tierra 88.730 cabezas de ganado merino trashumante. Vid. ALCALDE JIMÉNEZ, J.M ${ }^{a} .:$ «Señorío, trashumancia y conflictividad social en la Sierra de Yanguas (Siglos XVIII-XIX)i, Historia Social, 38 (2000), p. 78.

12 En concreto, según los datos proporcionados por M.C. Gerbet, en el ejercicio 1451-2 la mayor cabaña de Yanguas que aparece registrada tuvo 4.198 cabezas; en el ejercicio 1452-3 tuvo 5.900 cabezas; en el ejercicio 1453-4 tuvo 3.868 cabezas, y en el ejercicio 1560-1 la mayor fue de 5.751 cabezas.

13 En el ejercicio 1451-2 se registra a nombre de un vecino de Molinos un rebaño con 6.044 cabezas, y en el siguiente ejercicio, de 1452-3, un rebaño de 6.250. M.C. Gerbet entiende que se trata de Molinos de Razón, pero en buena lógica también podría ser Molinos de Duero. Sea como fuere, en Molinos de Razón no está constatada la presencia como vecinos en ningún momento de señores de ganados, aunque sí de pastores. Al igual ocurrió en Molinos de Duero hasta bien entrado el siglo XVII, cuando se instaló en esta diminuta aldea, que era un simple anejo de la vecina Salduero, la familia Pérez, que llegó a reunir numerosas cabezas de ganado trashumante, además de poner en funcionamiento una ambiciosa «empresa» de carretería. 
mos centrar nuestra atención en determinar hasta qué punto la información aportada por estos cuadernos puede considerarse como prueba de que la actividad ganadera trashumante había alcanzado un desarrollo mucho mayor a la altura de la primera mitad del siglo XV en la Tierra de Yanguas que en otras comarcas próximas, situadas más al sur, como era en concreto la Tierra de Soria.

En efecto, esta tesis ha sido propuesta recientemente por la profesora María Asenjo ${ }^{14}$, integrada en un modelo explicativo que considera que en la región soriana, y en cierta medida también en la segoviana, fueron los territorios de señorío los primeros en ofrecer las condiciones propicias para el desarrollo de la actividad ganadera trashumante, que sólo pasó a interesar a los habitantes de los territorios del realengo en fechas muy posteriores, que esta autora sitúa entre mediados del siglo XV y las primeras décadas del siglo XVI. Hasta ahora rara vez se había puesto en relación por los investigadores el desarrollo de la ganadería trashumante con el régimen jurisdiccional imperante en las comarcas de pastos de agostadero donde se avecindaban los dueños de los rebaños, y por ello la formulación de esta tesis representa un interesante cambio de orientación en la definición de los modelos explicativos sobre el origen y desarrollo de la trashumancia en Castilla, por lo cual merece la pena detenerse en su análisis y verificación.

Sostiene en concreto esta autora que la importancia de la ganadería trashumante en la Tierra de Soria es sólo perceptible a partir de la segunda mitad del siglo XV, mientras que con anterioridad sólo se documenta una actividad ganadera trashumante de cierta relevancia en los concejos de señorío que limitaban con el soriano por el norte, entre los que cita los de Yanguas, San Pedro Manrique y Magaña, además de en el concejo realengo de Ágreda ${ }^{15}$. De esta manera introduce un matiz que en parte cuestiona la validez de su modelo explicativo, porque parece admitir que la ganadería trashumante pudo desarrollarse desde fechas más tempranas en un concejo de realengo como Ágreda, aunque sin entrar a determinar por qué en él las condiciones eran más propicias para este más temprano desarrollo ganadero que en el de Soria. Y, al mismo tiempo, aporta un dato erróneo cuyo desmentido también contribuye a cuestionar la validez del modelo. Se trata de la inclusión de Magaña entre los concejos de señorío, cuando este lugar estuvo dependiendo jurisdiccionalmente de la ciudad de Soria hasta que en 1445 Juan II hizo merced del mismo, y de

14 Hay que destacar en particular ASENJo GonZÁlez, $\mathrm{M}^{\mathrm{a}}$.: Espacio y Sociedad en la Soria Medieval. Siglos XIII-XV, Soria, Diputación Provincial, 1999, pp. 268-325. Y «Los espacios ganaderos. Desarrollo e impacto de la ganadería trashumante en la Extremadura castellano-oriental a fines de la Edad Media», en Los rebaños de Gerión. Pastores y trashumancia en Iberia antigua y medieval, Madrid, Casa de Velázquez, 2001, pp. 71-108.

15 ASENJo GONZÁlez, M ${ }^{a}$.: Espacio y Sociedad..., p. 269. Más adelante en esta misma obra precisa que el despegue soriano, es decir, el de la ciudad de Soria y su Tierra, a la actividad ganadera trashumante está probado desde 1460 , y a partir de ahí se observa un constante crecimiento en los decenios posteriores (p.. 271).

Hispania, LXIV/3, núm. 218 (2004) 1045-1078 
otras varias aldeas a su alrededor, a Juan de Luna, entonces tenente de la fortaleza soriana ${ }^{16}$.

Pero, pasando a analizar el núcleo central del argumento propuesto por la profesora Asenjo para justificar su tesis, advertimos que se basa en el planteamiento de una neta contraposición entre los ámbitos jurisdiccionales de la Tierra de Yanguas, caracterizado como arquetipo de concejo señorial volcado desde fechas muy tempranas hacia la práctica de la ganadería trashumante, y la Tierra de Soria, propuesto como prototipo de concejo realengo en el que el interés de sus habitantes por esta actividad se despertó mucho más tarde, y no prendió entre los miembros de su oligarquía hasta prácticamente los comienzos del siglo XVI.

Este fuerte contraste entre los dos ámbitos se justifica en parte con las cifras proporcionadas por M.C. Gerbet en su estudio de los cuadernos de cuentas de la recaudación del peaje del puente de Capilla. Y, en efecto, según esta fuente, mientras que en el ejercicio de $1428-9$ pasaron por este puente 27 rebaños registrados a nombre de vecinos de Yanguas y su Tierra, que sumaron 58.087 cabezas, los correspondientes a ganaderos vecinos de lugares de la Tierra de Soria fueron tan sólo 8 , que sumaban apenas 18.121 cabezas. Se trata, pues, de un contraste notable, pero a partir de su constatación resulta muy arriesgado extraer conclusiones de carácter general, teniendo en cuenta el carácter parcial de la fuente, y que tampoco está suficientemente probado que los individuos al nombre de los cuales se registraron los ganados fuesen efectivamente sus dueños. Y a este respecto no debemos olvidar que en momentos posteriores fueron muchos los vecinos de aldeas de la Tierra de Yanguas que sirvieron como pastores y mayorales a grandes propietarios ganaderos de la ciudad y Tierra de Soria, y de otros ámbitos más meridionales, como, por ejemplo, la Tierra de Almazán.

Pero, además, por otro lado, las oscilaciones en el número de ganados registrados fueron muy fuertes de unos ejercicios a otros, y como consecuencia las distancias entre los dos ámbitos llegaron a convertirse en mínimas en algunos de ellos. Así ocurrió, por ejemplo, en el ejercicio de 1460-1, durante el que se registraron 28 rebaños a nombre de vecinos de la Tierra de Soria, que sumaron 48.579 cabezas, y otros 28 rebaños a nombre de vecinos de la Tierra de Yanguas, que sumaron 50.930 cabezas $^{17}$. Este hecho no ha pasado desapercibido para la profesora Asenjo, quien quizás por ello fijó precisamente en el año 1460

16 Sobre la pertenencia de Magaña a la Tierra de Soria vid. Diago Hernando, Máximo: «Expansión señorial en la Tierra de Soria en época Trastamara», Celtiberia, 74 (1987), pp. 204-6. «Repoblación e integración política en el reino de Castilla del ámbito de la Tierra de Soria», Revista de Investigación del Colegio Universitario de Soria, XI, 3 (1991-2), pp. 37-58. Y «El alcaide Juan de Luna: un hombre al servicio del Condestable Don Álvaro en la región soriana», Celtiberia, 81-82 (1991), pp. 59-85.

17 Reproducimos las cifras que proporciona ASENJO GONZÁLEZ, $M^{a} .:$ Espacio y Sociedad... p. 270. Estas cifras han de ser, no obstante, relativizadas, pues, por ejemplo, en 1461 incluye entre los lugares de la Tierra de Soria a Carrascosa y Pobar, que desde 1445 pertenecían al señorío de Juan de Luna. 
el inicio del despegue de la ganadería trashumante en la Tierra de Soria ${ }^{18}$. Pero, en cualquier caso, si ya entonces los ganaderos vecinos de lugares de este ámbito jurisdiccional que pasaron por el puente de Capilla sumaban cerca de 50.000 cabezas de ganado trashumante, parece muy improbable que se tratase de una actividad de reciente implantación.

Por el contrario, aunque ciertamente la escasez de documentación nos impide demostrar de forma contundente que en la Tierra de Soria la actividad ganadera trashumante ya se encontraba muy extendida durante la primera mitad del siglo XV, sí resulta al menos posible reunir una serie de significativos indicios que hacen muy verosímil esta tesis, a los cuales pasaremos revista a continuación.

Así, en primer lugar, tenemos que un número significativo de familias integradas en el grupo oligárquico soriano durante el siglo XV fueron ya entonces a su vez destacadas propietarias de rebaños de ganado trashumante. Es el caso, por ejemplo, de la familia Calderón, protagonista de un proceso de rápido ascenso social y político sin duda favorecido por los beneficios económicos obtenidos de su explotación ganadera trashumante.

El primer miembro de esta familia del que dan cuenta las genealogías es un tal Caballero del Río Cavado, que vivió en Villoslada de Cameros. Nada sabemos de él, pero el hecho de proceder de esta villa camerana nos invita a presumir que el interés de la familia por la ganadería trashumante se pueda remontar al menos hasta él, puesto que este lugar fue cuna de numerosos individuos dedicados a esta actividad. Hijo suyo fue Pedro García Cavallero, primer miembro de la familia que se asentó en Tierra de Soria, en concreto en la aldea serrana de Gallinero, auténtico vivero de ganaderos trashumantes durante los siglos XV y XVI. Tampoco de él sabemos mucho, pero presumimos que debió alcanzar una posición económica suficientemente holgada como para permitirse enviar a cursar estudios universitarios a su hijo Pedro García Calderón, quien obtuvo el título de bachiller, el cual le abrió las puertas para una brillante carrera política, no sólo en la ciudad de Soria, sino también en el ámbito cortesano, donde llegó a ocupar el oficio de alcalde de Corte y Rastro, que a su muerte en 1475 dejó en herencia a su hijo Andrés Calderón, entonces todavía bachiller, y más tarde licenciado ${ }^{19}$. Pues bien, Pedro García Calderón, además de un cortesano influyente y reputado miembro de la oligarquía soriana, fue a su vez, siguiendo la tradición familiar, propietario de ganados trashumantes, al igual que sus hermanos residentes en Gallinero. Y, en la siguiente generación, su hijo, el licenciado Andrés Calderón, protagonista de una carrera política aún

18 ASENJo GonZÁlez, Ma .: Espacio y Sociedad... p. 271.

19 AGS (=Archivo General de Simancas), RGS (= Registro General del Sello), II-1475. Nombramiento de alcalde de Corte y Rastro, con quitación y excusados, a favor del bachiller Andrés Calderón, en la vacante por muerte de su padre Pedro García Calderón. Ibid. fol. 170. Su nombramiento como consejero real.

Hispania, LXIV/3, núm. 218 (2004) 1045-1078 
más exitosa que la del padre ${ }^{20}$, continuó manteniendo la explotación ganadera trashumante, al igual que muchos de sus primos y demás familiares residentes en Gallinero. Y de este modo el apellido Calderón se consolidó como uno de los más frecuentes en la documentación mesteña soriana de las últimas décadas del siglo XV y de las primeras del siglo $\mathrm{XVI}^{21}$.

Un segundo ejemplo de familia integrada en el grupo oligárquico soriano del siglo XV, sobre la que disponemos de bastantes referencias que prueban su fuerte interés por la trashumancia, nos lo proporciona la de los Vera, a la que pertenecieron, entre otros, el regidor Juan de Vera, su hermano Rodrigo de Vera, señor de Hinojosa de la Sierra y varias veces procurador a Cortes por Soria entre 1445 y 1458 , y el hijo del primero, Hernando de Vera, avecindado en Vinuesa. De estos tres individuos, el que presenta un perfil más modesto como propietario ganadero es el primero, el regidor Juan de Vera, quien al otorgar su testamento en 1458 declaró poseer 800 ovejas y carneros y 200 cabras, además de 200 vacas y novillos. Mucha más relevancia alcanzó, sin embargo, su hermano Rodrigo de Vera, fallecido hacia 1471, a quien diversos testigos le atribuyeron la posesión de en torno a 9.000 cabezas de ganado ovino trashumante, que llevaba a pastar en invierno a la comarca de la Serena e incluso al reino de Portugal. Y, además de esto, tenemos constancia de que negociaba regularmente la venta de sus lanas en las ferias de Medina del Campo con mercaderes burgaleses como Ortega de Carrión ${ }^{22}$. Y una posición igualmente destacada alcanzó en la siguiente generación como propietario de ganados trashumantes Hernando de Vera, vecino de Vinuesa, hijo de Juan y sobrino de Rodrigo, quien en el momento de su muerte poseía cuatro rebaños de ovejas, un rebaño de carneros viejos y 1.600 corderos, además de 3.300 cabezas de posesión en Extremadura ${ }^{23}$.

Un tercer ejemplo, por fin, lo tenemos en la familia del doctor Pedro Álvarez de Morales, hidalgo miembro del linaje de los Morales Hondoneros, que desempeñó durante muchos años el oficio de açesor o letrado del concejo de Soria, y gozó además de favor en la Corte, que le valió la obtención de un privilegio regio para la conversión en término redondo de su heredamiento de Malluembre ${ }^{24}$. Poco sabemos sobre su perfil como propietario ganadero trashumante, pero es

20 Fue nombrado por los Reyes Católicos primer corregidor de la ciudad de Granada tras su conquista. Vid. Peinado Santaella, R.G.: «Una propiedad latifundista en el Reino de Granada: la hacienda del corregidor Andrés Calderón (1492-1500)», Chronica Nova, 22 (1995), pp. 303-355.

21 A principios del siglo XVI Juan García Calderón, vecino de Gallinero, era un destacado propietario ganadero. Nos lo confirma el hecho de que al morir su mujer en el año 1513 ésta era propietaria de más de 4.000 cabezas de ganado ovino y 133 cabezas de vacuno. Consta por copia del inventario post mortem, en AChV (=Archivo de la Chancillería de Valladolid), P.C. (=Pleitos Civiles) Taboada, F. (=Fenecidos), envoltorio 291-12.

22 Toda la información relativa a Juan de Vera y a su hermano Rodrigo de Vera la tomamos de declaraciones de testigos y documentos en AChV, P.C. Z. y Walls, F. C. 303-1, 304-1, 305-1 y 306-1 (Documentación del pleito de Hinojosa).

23 Según inventario de bienes post mortem, en AChV, P.C. Pérez Alonso, F. C. 405-1.

24 Este privilegio en AGS, Escribanía Mayor de Rentas, Mercedes y Privilegios, leg. 85, fol. 50. 
seguro que lo fue porque en 1494 un tal Juan Jiménez, vecino de la aldea serrana de Suellacabras, que entonces contaba con 60 años de edad, declaró que había guardado ganados suyos, y más adelante había servido como mayoral a su hijo el licenciado Diego de Morales, oidor de la Chancillería de Valladolid, y procurador a Cortes por Soria en las de Madrigal de $1476{ }^{25}$. A este último lo encontramos, en efecto, mencionado en varias ocasiones entre los asistentes a las asambleas mesteñas, según atestiguan los libros de actas conservados a partir del año 1499. Y en el año de su muerte, ocurrida en 1505, nos consta que poseía un rebaño de ganado ovino trashumante de cerca de 1.800 cabezas ${ }^{26}$. Ciertamente no se trataba de una cabaña de grandes dimensiones, en comparación con las que proliferaron en Soria durante los siglos XVI y XVII, y tampoco representaba el elemento principal de su hacienda, ni el que le proporcionaba mayores ingresos ${ }^{27}$. Pero, a pesar de todo, estamos ante un número nada desdeñable de cabezas de ganado, que refuerza nuestro convencimiento de que varias relevantes familias de la oligarquía soriana mantuvieron un fuerte interés en la actividad ganadera trashumante desde, al menos, mediados del siglo XV, a pesar de que todavía no la hubieran convertido en el pilar de sus economías familiares, al modo como terminó siéndolo para la mayoría en el transcurso del siglo XVI. Y, en efecto, a los ejemplos aludidos se podrían añadir otros varios más, que, no obstante, no vamos a entrar a detallar para no resultar excesivamente prolijos ${ }^{28}$.

25 Las declaraciones de este testigo en AHN (=Archivo Histórico Nacional), Osuna, 353-12$8 v$. y ss.

26 Según declaración de su mayoral, en la primavera de ese año se habían esquilado 1.770 cabezas de su propiedad, habiéndose obtenido de la venta de sus lanas un total de $90.270 \mathrm{mrs}$., pagadas a razón de un real y medio cada una. Vid. AChV, P.C. Varela, F. C. 1673-2.

27 En concreto el monto total de los ingresos del licenciado en el año 1505 se estimó en alrededor de $359.700 \mathrm{mrs}$. de los cuales en torno a 182.430 correspondían a las rentas de cereal (En el documento sólo se informa de que estas rentas ascendieron a 1.244 fanegas, dos partes trigo, y una cebada y centeno. Esta cantidad la hemos convertido en mrs. aplicando los precios de tasa entonces comúnmente usados. La cifra resultante es, por tanto, sólo orientativa). A esta partida seguía en importancia la de la venta de las lanas, que proporcionó $90.270 \mathrm{mrs}$. El arrendamiento para pastos del término redondo de Malluembre aportó $65.000 \mathrm{mrs}$. Y los demás ingresos declarados se reducían a un juro de 16.000 mrs. y a las rentas de varias casas, que sumaban 5.370 mrs., aparte de 112 gallinas y 46 carretadas de leña. Estimamos, no obstante, que en esta relación no se incluyeron todos los ingresos, pues, por ejemplo, no aparecen referencias a capítulos tan importantes como el de la venta de carneros, o el de los sueldos y quitaciones que el licenciado percibía por razón de sus oficios cortesanos.

28 A título de complemento haremos constar que el caballero Ramir Yáñez de Santa Cruz, quien fue alguacil de Soria en 1469 , según un inventario de su hacienda fechado en el año 1478, era entonces dueño de un rebaño de ganado ovino trashumante que comprendía 1.000 ovejas y 517 corderos, y además había heredado de su padre la mitad de una casa de lavadero en Villoslada. Tomamos estas noticias de AChV, P.C. Z. y Balboa, F. C. 1113. Sobre otras familias destacadas de la oligarquía soriana, como los Beteta o los Morales, disponemos de datos de carácter más vago que prueban su vinculación con la Mesta y la ganadería trashumante, pero no de datos cuantitativos que nos permitan estimar su rango como propietarios ganaderos.

Hispania, LXIV/3, núm. 218 (2004) 1045-1078 
En cualquier caso entendemos que los referidos ejemplos permiten al menos matizar la tesis de la profesora Asenjo que sostiene que los caballeros sorianos se limitaron hasta el año 1480, aproximadamente, a «parasitar» a los ganaderos mesteños, imponiendo onerosos tributos a los rebaños de ganado trashumante que transitaban por la Tierra de Soria camino de los pastos de invierno, y que sólo a partir de esa fecha cambiaron radicalmente de estrategia y actitud, pasando a aunar intereses con los mesteños, al volcarse ellos mismos de forma directa en la explotación de rebaños de ganado trashumante ${ }^{29}$. Varias noticias proporcionadas por la escasa documentación conservada confirman, por el contrario, que durante todo el siglo XV destacados caballeros sorianos, señores de nutridos rebaños de ganado trashumante, formaron parte de la Mesta, aunque al mismo tiempo es cierto que, en este período, el interés por la ganadería trashumante todavía no se despertó de forma generalizada entre las principales familias de la oligarquía. Por el contrario, muchas continuaron manteniéndose totalmente al margen de esta actividad, que, por otro lado, tampoco representó la principal fuente de ingresos para aquéllas que se interesaron por la misma, dado que en prácticamente ningún caso llegaron a reunir cabañas de muy grandes dimensiones, al tiempo que contaban con otras importantes fuentes de ingresos, entre las que entonces ocupaba un lugar preferente la transferencia de rentas por la monarquía a través de sueldos, mercedes y privilegios ${ }^{30}$.

De hecho bastantes indicios invitan a presumir que, durante el siglo $\mathrm{XV}, \mathrm{y}$ hasta bien avanzada la primera mitad del siglo XVI, la mayoría de los principales propietarios de ganados trashumantes de Soria y su Tierra no estuvieron integrados en el grupo oligárquico, sino que fueron personas avecindadas en comarcas rurales, preferentemente serranas, que en muchos casos no tenían reconocida siquiera la condición hidalga. Las referencias documentales disponibles para proceder a la identificación de estos ganaderos apartados de los círculos oligárquicos resultan, de nuevo, desalentadoramente escasas. Pero al menos algunas existen, y permiten abundar en la demostración de la tesis de que durante la primera mitad del siglo XV la ganadería trashumante alcanzó ya un grado de desarrollo en la Tierra de Soria, sobre todo en su sector serrano, que nada tenía que envidiar al que simultáneamente estaba experimentando en la Tierra de Yanguas.

Así, en primer lugar, la documentación de la primera mitad del siglo XV nos informa sobre la dedicación a la ganadería trashumante y sobre la activa participación en la institución mesteña de familias de origen serrano que en el siglo XVI se contaron entre las propietarias de las mayores cabañas de la Tierra de Soria. Es el caso de la familia de los Vinuesa, originaria de la aldea serrana de Gallinero, a la que pertenecía Juan García de Vinuesa, propietario ganadero

29 Defiende esta tesis en «Los espacios ganaderos... p. 104.

30 Vid. Diago Hernando, Máximo: «Caballeros y ganaderos. Evolución del perfil socioeconómico de la oligarquía soriana en los siglos XV y XVI», Hispania, 184 (1993), pp. 451-95. 
que en 1428 desempeñaba el oficio de escribano mayor de mestas y cañadas ${ }^{31}$. Varios años más tarde, en una deposición de testigos, varios declarantes coincidieron en reconocer que otro miembro de esta familia, Pedro García de Vinuesa, el Viejo, era una autoridad en el conocimiento de los privilegios de la Mes$\mathrm{ta}^{32}$. Este último, además, fundó un mayorazgo en 1447 en favor de su hijo Juan García de Vinuesa, en el que incluyó unas casas en Gallinero con su esquiladero, por lo cual cabe presumir que debió alcanzar una destacada posición económi$\mathrm{ca}$, que, en cualquier caso, continuaron reforzando sus sucesores en las siguientes generaciones, sentando así las bases para que a mediados del siglo XVI el regidor Juan de Vinuesa, primer miembro de la familia que se incorporó al grupo oligárquico soriano, llegase a reunir una de las mayores fortunas de Soria y su Tierra33.

Además de los Vinuesa, otras diversas familias procedentes de aldeas serranas de la Tierra de Soria pueden ser identificadas como propietarias de rebaños de ganado trashumante que, gracias a su dedicación a esta actividad entonces en expansión, consiguieron mejorar de forma apreciable su posición económica, sentando así las bases para su posterior promoción en los terrenos social y político. Muchas de estas familias fueron incluso en sus orígenes pecheras. Así nos lo permite comprobar, por ejemplo, un documento del año 1447 que recoge una relación de las aportaciones efectuadas por 165 vecinos pecheros de aldeas de la Tierra de Soria para recaudar la cantidad que Juan II reclamó como préstamo forzoso a la Universidad de la Tierra, para afrontar los gastos de defensa del reino frente al previsible ataque del rey de Navarra, cuyos partidarios acababan de apoderarse de la fortaleza de Peñalcázar ${ }^{34}$. Y es que algunos de los mayores contribuyentes en este préstamo pueden ser identificados como ganaderos trashumantes avecindados en aldeas serranas, pertenecientes además a familias que con posterioridad consiguieron acceder a la hidalguía.

Es el caso en primer lugar del mayor contribuyente, Martín Sánchez de Montenegro, vecino de Vinuesa, quien prestó $3.000 \mathrm{mrs}$. No es mucho lo que sabemos sobre este individuo, pero sí nos consta que sus descendientes fueron destacados señores de ganados trashumantes durante los siglos XVI y XVII, no

31 LuIs LóPez, Carmelo: Documentación Medieval de los Archivos Municipales de La Adrada, Candeleda, Higuera de las Dueñas y Sotillo de la Adrada, Ávila, 1993, pp. 156-8. Carta otorgada en El Almendral, 13-XI-1428, por Pedro Ruiz de Gaona, guarda del rey y su alcalde entregador mayor de las mestas y cañadas por Gómez Carrillo, hijo de Álvaro Carrillo, confirmando una dehesa boyal al concejo de La Higuera, del señorío de las dueñas de San Benito de Ávila. El documento es suscrito por Fernando Alfonso de La Muela, «escribano de nuestro señor el rey de las mestas y cañadas, en lugar de Juan García de Vinuesa, escribano mayor de las dichas mestas y cañadas».

32 AHN, Osuna, leg. 351-3-2-4.

33 Sobre los sucesivos mayorazgos fundados por la familia Vinuesa, de los cuales el primero fue el ya referido de 1447, Vid. BARTOLOMÉ MARTínEZ, Bernabé: «Los Vinuesa: Una familia, un mayorazgo y muchos pleitos", Celtiberia, 65 (1983). Sobre la incorporación de Juan de Vinuesa al grupo oligárquico soriano Vid. DiAGo HerNANDO, Máximo: «Caballeros y ganaderos...», pp. 477 y ss.

34 Archivo Municipal de Soria, docs. singulares, $\mathrm{n}^{\circ} .63$

Hispania, LXIV/3, núm. 218 (2004) 1045-1078 
sólo en Vinuesa sino también en otros lugares de su entorno; hoy pertenecientes a la comunidad riojana, como Brieva y Villoslada de Cameros. Y, por otro lado, también tenemos noticia de que en el transcurso de la segunda mitad del siglo XV diversos miembros de esta familia consiguieron acceder al estamento hidalgo por la vía llamada de los «caballeros pardos», consistente en acudir a servir al rey en alguna guerra, para ser armados caballeros en el transcurso de la misma ${ }^{35}$.

Por debajo de Martín Sánchez de Montenegro, hubo en 1447 otros dos grandes contribuyentes, que aportaron 2.500 mrs. Uno, Romero García, vecino de Vilviestre, consideramos probable que tuviese como principal dedicación la carretería, ya que su lugar de residencia era uno de las principales núcleos carreteros de la Tierra de Soria. Y el otro, Martín García, vecino entonces de la pequeña aldea serrana de Arguijo, nos consta que era un ganadero trashumante, miembro de una dinámica familia , bien conocida por su dedicación a la actividad ganadera trashumante y por su participación en la institución mesteña durante todo el siglo XV y las primeras décadas del siglo XVI, hasta que sus principales representantes trasladaron su residencia a Sevilla, para volcar su atención en otros negocios relacionados con América.

En efecto, ya en los cuadernos de cuentas de la recaudación del peaje del puente de Capilla, dados a conocer por M.C. Gerbet, aparece mencionado un Martín García de Arguijo, identificado como vecino de Soria, quien en 1428 pasó 2.500 cabezas de ovino por dicho puente. Y en esta misma fuente documental se hace referencia a un tal Juan García de Arguijo, al informarnos que durante el invernadero de 1428-9 sus rebaños, que guardaba Juan García de Laguna, habían producido 1.270 corderos, por los cuales se pagaron al señor de Capilla 25 carneros. Nada sabemos con certeza sobre el grado de parentesco existente entre estos dos individuos, que bien podrían haber sido hermanos, ni sobre su relación con el Martín García de Arguijo que aparece entre los mayores contribuyentes en el préstamo de 1447. Pero resulta significativo que estos mismos patronímicos se continuaron repitiendo entre los García de Arguijo durante la segunda mitad del siglo XV y en la primera del XVI, por lo que no consideramos demasiado aventurado concluir que todos formaban parte de una misma familia.

En la segunda mitad del siglo XV las noticias sobre miembros de dicha familia comienzan a resultar más abundantes, y en particular hay que destacar

35 Vid. AHN, Consejos, leg. 25.614. Documentación sobre los pleitos de hidalguía seguidos por varios miembros de la familia Sánchez Montenegro, de Vinuesa, en las décadas de 1520 y 1530. Se hace constar en las declaraciones de testigos que el acceso a la hidalguía de éstos o sus antepasados se había producido por la vía de los «caballeros pardos». En concreto varios testigos se refirieron a la «guerra» de Toro (es decir, la batalla de Toro de 1475, librada por Fernando el Católico contra el rey de Portugal), en que tres hermanos de esta familia se habían armado "caballeros pardos». Algún testigo por su parte declaró que Martín Sánchez de Montenegro, bisabuelo de los que litigaron su hidalguía a principios del siglo XVI, se armó caballero «en otra guerra en vida del rey Don Juan». Debía tratarse, por tanto, del incluido en la relación de prestamistas del año 1447. 
las referentes a Martín García de Arguijo, quien es identificado a comienzos del reinado de los Reyes Católicos como residente en San Andrés de Almarza, aldea de la Tierra de Soria muy próxima a Arguijo. Diversos indicios prueban que este inquieto y dinámico personaje, que de San Andrés de Almarza pasó luego a residir a la ciudad de Soria, y finalmente a la de Sevilla ${ }^{36}$, fue un activo ganadero trashumante, aunque no parece que llegase a contarse entre los mayores propietarios de la Tierra de Soria ${ }^{37}$. Y sabemos, además, que la mejora de su posición económica, conseguida sin duda gracias a los beneficios proporcionados por la gestión de su cabaña trashumante, le permitió dar importantes pasos en su promoción sociopolítica, logrando acceder al estamento hidalgo gracias a la obtención de un privilegio de hidalguía del rey Enrique IV, que lo expidió en su favor en el Real de Simancas, a donde había acudido a combatir a caballo ${ }^{38}$.

Los Sánchez Montenegro y los García de Arguijo no fueron los únicos pecheros residentes en aldeas serranas de la Tierra de Soria que en el transcurso del siglo XV consiguieron reunir importantes rebaños de ganado trashumante, sentando así las bases para la prosperidad económica y posterior ascenso social y político de sus familias. Hubo otros más, aunque la falta de documentación dificulta la reconstrucción de sus trayectorias, y sobre todo impide retrotraerlas hasta la primera mitad del siglo XV, o a fechas anteriores ${ }^{39}$. Pero los ejemplos

36 Sobre la interesante trayectoria de los García de Arguijo en Sevilla, en Canarias y en América, está elaborando un trabajo de investigación el profesor norteamericano Stanko VRANITZ, a quien debemos muchas de las informaciones sobre esta faceta de la familia, que confirma el carácter emprendedor de la misma.

37 Así lo sugiere, por ejemplo, la cantidad por la que se igualó para el pago de sus alcabalas en el año 1506 , que fue de $2.500 \mathrm{mrs}$. Pues, aunque se trataba de una cifra sin duda importante, estaba muy alejada de los $12.000 \mathrm{mrs}$. por los que se igualó Juan de Vinuesa, vecino de Gallinero, o los 16.500 por los que se igualaron tres miembros de la familia Calderón, de esa misma aldea. Para más detalles vid. la lista de igualados de las alcabalas de la Tierra de Soria de 1506 en Diago HernanDO, Máximo: «El comercio de las lanas en Soria en época de los Reyes Católicos», Celtiberia, 78 (1989), pp. 62-5.

38 AGS, RGS, X-1483, fol. 71. Martín García de Arguijo, vecino de San Andrés de Almarza, seguía pleito contra la Universidad de la Tierra de Soria sobre su hidalguía.

39 Con cierto esfuerzo se pueden identificar algunas otras familias que responden al mismo perfil que las de Sánchez Montenegro y García de Arguijo. Sería el caso, por ejemplo, de los Martínez de Almarza. Algunas breves referencias al proceso de ascenso de esta familia, a la que pertenecieron destacados eclesiásticos sorianos de los siglos XV y XVI, entre ellos el chantre de Soria, el bachiller Pedro Fernández de Almarza, quien fue nombrado testamentario por el licenciado Calderón, primer corregidor de Granada, en DiAGo HerNANDO, Máximo: «Soria y su Tierra en el obispado de Osma durante los siglos XV y XVI. Organización eclesiástica y práctica religiosa», XIV Centenario Diócesis Osma-Soria. Premios de Investigación, Soria, Diputación Provincial, 2000, p. 498. Otra noticia que confirma la dedicación ganadera de esta familia es proporcionada en VARONA GARCíA, Antonia: Cartas ejecutorias del Archivo de la Real Chancillería de Valladolid (1395-1490), Valladolid, 2001. Doc. $\mathrm{n}^{\circ}$. 109. Valladolid, 6-VII-1486. Referencia a la denuncia presentada por Diego de Medrano, vecino de Atienza, contra Pedro de Córdoba, alcaide de El Pardo, acusándole de

Hispania, LXIV/3, núm. 218 (2004) 1045-1078 
aducidos pueden considerarse suficientes para probar que ya en el transcurso de la primera mitad del siglo XV la ganadería trashumante en el sector serrano de la Tierra de Soria había alcanzado suficiente desarrollo como para que comenzasen a despuntar algunas familias que debían su prosperidad a los saneados beneficios que estaba empezando a reportar esta actividad.

$Y$, por otro lado, también resulta posible comprobar que junto a estas prósperas familias coexistieron en las referidas aldeas serranas otras muchas de modesta posición económica que practicaron la trashumancia con pequeños rebaños, con el único objetivo de contribuir a su subsistencia. En efecto, un documento notarial del año 1443 que recoge un contrato de obligación suscrito por varios vecinos de La Losilla - aldea perteneciente en aquel momento a la Tierra de Soria, aunque dos años después fue entregada en señorío junto con Magaña y otras aldeas a Juan de Luna - con un mercader soriano, el escribano Juan Rodríguez de Soria, nos proporciona un magnífico testimonio de esta realidad, que muy probablemente nos habría permanecido totalmente oculta de no haberse preservado por mero azar este singular documento en el fondo nobiliario de Osuna, en el que lo localizamos por casualidad, puesto que ningún instrumento descriptivo hacía prever su presencia en él 40

La referida carta de obligación fue suscrita a fines de septiembre de 1443 , cuando los ganados estaban a punto de partir hacia el sur en busca de los pastos de invierno, y en ella los otorgantes se comprometieron a entregar a finales de junio del año siguiente, en torno al día de San Juan, a Juan Rodríguez de Soria un total de 250 arrobas de lana, a cambio de recibir de éste un adelanto de dinero de $50 \mathrm{mrs}$. por arroba, al cual nos consta, por anotaciones realizadas con posterioridad en el propio documento, que se añadió después otro adelanto de $600 \mathrm{mrs}$. efectuado el día 4 de octubre de 1443 , y, por fin, otro de 5 doblas de la banda "para enviar a Estremo". De estas noticias se deduce, por tanto, que los vendedores de la lana eran individuos que se desenvolvían en una posición financiera poco desahogada, y precisaban que se les efectuasen importantes adelantos de dinero para poder afrontar los gastos que conllevaba el envío de sus ganados a invernar a las dehesas del sur. Y, por su parte, el detalle de las cantidades de lana que cada uno de ellos se comprometió a entregar nos confirma que se trataba de campesinos de muy modestos medios, entre los que sólo despuntaba alguno con posición medianamente acomodada. Este último era el caso de Pedro López, quien se comprometió a entregar 100 arrobas, por lo que cabe presumir que debía poseer alrededor de 500 cabezas de ganado

haberle tomado a su abuelo Pedro Fernández de Almarza 750 carneros y ovejas, y 27 cabras, cuando en 1474 pasó por las inmediaciones de dicha fortaleza con sus pastores.

40 El documento en cuestión, que es un contrato otorgado en La Losilla, 24-IX-1443, se conserva en AHN, Osuna, 2244-10-9, pieza 20. El motivo de su conservación es que fue presentado como prueba documental por la ciudad de Soria para demostrar la pertenencia de Magaña y sus aldeas a su jurisdicción, cuando en la primera mitad del siglo XVI siguió pleito contra los descendientes de Juan de Luna para que le fuesen devueltos estos territorios. 
ovino mayor, es decir, entre ovejas y carneros. Un rebaño mucho más pequeño poseería su hermano Juan Martínez, quien se comprometió a entregar tan sólo 30 arrobas, y también propietarios relativamente modestos serían Martín Fernández, quien se obligó a entregar 60, y Blasco Martínez, quien tan sólo debía entregar 28, a las que se sumarían otras 8 de su hijo Blasco, el cual suponemos que debía estar ya entonces emancipado, probablemente casado, y por ello disponía de su propio, aunque minúsculo, rebaño. E igualmente minúsculos debían ser los rebaños de los otros vecinos que participaron en esta venta colectiva de lanas, pues Juan Fernández se comprometió, en su nombre y en el de su hermana, a entregar 12 arrobas, Pedro Sánchez se obligó a la entrega de 6 y Martín, criado de Pedro López, de otras 6.

De todos los que se obligaron a entregar cantidades por debajo de las 20 arrobas, y que en buena lógica debían ser propietarios de rebaños de menos de 100 cabezas, sólo este último aparece expresamente identificado como criado, que en este contexto viene a ser lo mismo que pastor, y precisamente del ganadero más acomodado de todos cuantos concertaron la operación, es decir, el que poseía en torno a 500 cabezas. Pero es muy probable que también los otros, al ser poseedores de rebaños tan minúsculos, trabajasen como pastores al servicio de otros propietarios, pues de otro modo tropezarían con serias dificultades para asegurar la subsistencia de sus familias. Y, en efecto, en momentos posteriores numerosas referencias documentales nos confirman que los dueños de grandes cabañas de la región soriana reclutaron a la práctica totalidad de sus mayorales y pastores en aldeas de las comarcas serranas de la Tierra de Soria del tipo de La Losilla.

En cualquier caso este documento, conservado por mero azar, nos proporciona una irrefutable prueba de que en las comarcas serranas de la Tierra de Soria a mediados del siglo XV la ganadería trashumante era una actividad muy arraigada entre la población campesina ${ }^{41}$, que aseguraba una precaria subsistencia a muchos de sus miembros, que sólo poseían unas pocas cabezas y probablemente por ello en muchos casos se veían forzados a poner su fuerza de trabajo y su experiencia al servicio de otros ganaderos más acomodados, en unas ocasiones convecinos suyos, y en otras residentes en núcleos urbanos relativamente alejados. La lástima es que no se hayan conservado más documentos de este tipo, que en buena lógica deberíamos hoy poder contar por cientos si hubiese habido más suerte en la preservación de los protocolos notariales.

Recapitulando, por tanto, entendemos que no hay motivos para retrasar el momento del despegue de la actividad ganadera trashumante y de la implanta-

41 Las condiciones de fijación del precio de la lana confirman que en las otras aldeas del entorno de la Losilla también había propietarios ganaderos que pondrían en el mercado lanas de calidad semejante a las de los vecinos de aquella aldea. Así se acordó que la arroba de lana se les pagase al precio a como se vendiese este año la lana de Carrascosa, Povar, Suellacabras y Narros, «ni como la de más ni como la de menos». Esta cláusula del precio «mediado» siguió aplicándose en este tipo de contratos durante los siglos XVI y XVII.

Hispania, LXIV/3, núm. 218 (2004) 1045-1078 
ción de la institución mesteña en la Tierra de Soria hasta fechas tan tardías como las propuestas por la profesora Asenjo, que a nuestro entender exagera el retraso en este terreno de esta jurisdicción realenga con respecto a los territorios de señorío localizados en su flanco septentrional. De hecho esta autora tiende a equiparar ganaderos mesteños con vecinos de Yanguas y de Cameros siempre que se refiere a fechas anteriores al reinado de los Reyes Católicos. Pero al proceder así olvida que en el seno del partido mesteño soriano la ciudad de Soria y su Tierra tuvo desde el primer momento un fuerte peso específico. $Y$ así nos lo confirma, por ejemplo, el hecho de que, según atestiguan los libros de actas de la Mesta, conservados a partir del año 1499, este partido se encontraba dividido entonces en dos sectores, que se alternaban en la designación de los oficiales que cada año le correspondía nombrar, uno llamado de «aquende la sierra», que abarcaba la ciudad de Soria y su Tierra, y otro de «allende la sierra», en el que se integraban Yanguas, San Pedro Manrique, varias villas cameranas y Ágreda. Los ganaderos de Soria y su Tierra tenían, por tanto, reconocido el derecho a proveer la mitad de los oficios del partido mesteño soriano, y este privilegio resulta difícilmente explicable si se admite que hasta finales del siglo XV se habían mantenido al margen de la Mesta, como sugiere la profesora Asenjo.

Por otro lado estimamos poco convincente la explicación propuesta para dar cuenta de la presencia de ganaderos trashumantes en las comarcas serranas de la Tierra de Soria en fechas relativamente tempranas del siglo XV, que, aunque se constata, tiende a ser minusvalorada. En efecto, da la impresión de que para la profesora Asenjo la principal razón que explica este fenómeno radica en el fuerte estímulo que les proporcionó su mayor proximidad geográfica respecto a los concejos de señorío ${ }^{42}$. Y de este modo se da a entender que la adopción de las formas de explotación ganadera trashumante se produjo en los territorios del realengo de la región soriana en virtud de procesos de imitación de un modelo originado en territorios de señorío.

El sentido común nos lleva, sin embargo, a tomar en consideración otras explicaciones tanto o más plausibles para este fenómeno de la más temprana vocación ganadera trashumante del sector septentrional de la Tierra de Soria. Entre ellas habría que destacar las relacionadas con los factores climatológicos y edafológicos, pues no se ha de perder de vista que en las comarcas serranas del Sistema Ibérico soriano una poderosa razón que hasta bien entrado el siglo $\mathrm{XX}$ ha empujado a muchos ganaderos a trashumar con sus rebaños en invierno ha radicado en la imposibilidad de mantenerlos en el campo durante la dura estación invernal. Ciertamente también a los campesinos avecindados en las tierras llanas de esta misma región se les ha planteado siempre este mismo problema. Pero el rigor de la estación nunca ha sido tan acusado en dichas co-

42 AsEnjo GonZÁlez, Ma $M^{a}$ : «Los espacios ganaderos...» p. 77. Habla de «el importante y temprano desarrollo que la ganadería trashumante conoció en algunos lugares de la zona norte del concejo de Soria, debido al estímulo de la proximidad de los concejos ganaderos de señorío».

Hispania, LXIV/3, núm. 218 (2004) 1045-1078 
marcas, donde las nevadas son menos frecuentes y copiosas, y, además, en ellas la dependencia de la ganadería como medio de vida también ha sido y es mucho menor, debido a las mejores condiciones imperantes para el cultivo del cereal e incluso, aunque sólo en algunas, de la viña.

La profesora Asenjo entiende que la más temprana orientación de los habitantes de la Tierra de Yanguas y otros lugares de señorío de la sierra soriana hacia la trashumancia estuvo forzada por la falta de pastos, que les obligó a llevar sus ganados a Extremadura ${ }^{43}$. Pero no explica por qué esta falta de pastos era mayor en los territorios de señorío que en los de realengo. Y, sobre todo, olvida advertir que la misma tenía un marcado carácter estacional, es decir, que sólo se planteaba de forma acuciante en invierno, por razones climáticas, que afectaban igualmente a los territorios de realengo. Pues, desde el punto de vista de la regulación del aprovechamiento de pastos, el régimen señorial no tuvo apenas incidencia ni en la Tierra de Yanguas ni en los demás señoríos de su entorno, hasta el punto de que a los propios señores de la villa, los Arellano, se les llegaron a imponer severas limitaciones en el número de ganados que podían meter a pastar libremente en sus términos ${ }^{44}$.

El modelo explicativo de la profesora Asenjo se basa, no obstante, en el convencimiento de que la considerable extensión de la Tierra de Soria, y la abundancia de tierras de pasto en su interior, posibilitaron hasta prácticamente el final de la Edad Media el mantenimiento de una importante actividad ganadera trasterminante, es decir, basada en la realización de cortos recorridos con los ganados en busca de pastos, sin salir de la jurisdicción ${ }^{45}$. Pero este punto de vista resulta difícil de conciliar con la realidad de que en el espacio abarcado por la Tierra de Soria las condiciones climatológicas en invierno impedían mantener grandes rebaños, por mucha libertad de que se disfrutase para desplazarlos por dicho espacio en busca de pastos, pues las heladas impedían entonces el crecimiento de los mismos, y los propios ganados corrían el peligro de perecer o debilitarse en exceso si dormían a la intemperie en noches de riguroso frío. En estas condiciones resultaba imperioso buscar cobijo y alimento para los ganados para un período de tiempo relativamente largo, y no era nada fácil conseguirlo si se poseían rebaños de muchos cientos o miles de cabezas. De ahí que, hasta tiempos muy recientes, cuantos han reunido rebaños de cierto tamaño en la Tierra de Soria, al igual que en otras jurisdicciones de alrededor, no han tenido otra opción que trasladarlos fuera de la jurisdicción durante la estación invernal. Y así lo han venido haciendo siglo tras siglo no sólo los dueños

43 ASENJO GONZÁLEZ, $\mathbf{M}^{\mathrm{a}}$. :»Los espacios ganaderos...», p. 80. Sostiene que el reto que tenía ante sí la Mesta a fines del siglo XV era «dejar de ser una organización de ganaderos procedentes de las tierras de señorío, que por falta de pastos debían llevar sus ganados a Extremos, y lograr interesar a las oligarquías urbanas en el proyecto».

44 Sobre esta cuestión vid. Diago Hernando, Máximo: Soria en la Baja Edad Media. Espacio rural y economía agraria, Madrid, Editorial Complutense, 1993, pp. 68-74.

45 ASENJO GONZÁLEZ, $\mathbf{M}^{\mathrm{a}}$.: «Los espacios ganaderos...», p.76. 
de merinas practicantes de la trashumancia, sino también los propietarios de ovejas de otras razas estantes que en invierno se veían forzados a llevarlas a las tierras más templadas de los vecinos reinos de Aragón y Navarra.

En suma, por tanto, no creemos que unas hipotéticas mejores condiciones para la práctica de la ganadería trasterminante en el interior de la Tierra de Soria propiciasen el más tardío despegue de la actividad ganadera trashumante en esta jurisdicción en relación con los territorios de señorío situados en su flanco septentrional. Y, al mismo tiempo, no nos cabe ninguna duda de que el hecho de que esta actividad comenzase a desarrollarse más tempranamente en las aldeas de la Tierra más próximas a dichos señoríos nada tuvo que ver con la proximidad geográfica a los mismos, sino que fue consecuencia de que compartían con ellos unas mismas condiciones climatológicas y edafológicas que hacían atractiva la opción de mantener los rebaños de ganado ovino en régimen trashumante.

Pero otro factor clave no tenido en cuenta en el modelo de la profesora Asenjo, que sin embargo contribuyó de forma determinante a consolidar la opción por la trashumancia en las sierras sorianas, fue el fuerte incremento de la demanda de lana fina en los mercados exteriores que tuvo lugar en el transcurso del siglo XV. En efecto, el régimen de vida de las ovejas merinas trashumantes contribuía de forma decisiva a mejorar la calidad de las fibras que éstas producían, que por ello alcanzaban mayores precios y encontraban mejor acogida en el mercado, muy en especial en el internacional ${ }^{16}$. Y la demanda de lanas fue un factor clave para explicar el desarrollo de la trashumancia en tierras sorianas, puesto que la venta de este producto representó, al menos a partir del siglo XV, el pilar sobre el que se sustentaron las explotaciones ganaderas trashumantes, habida cuenta que los ingresos obtenidos de la venta de ganado para carne, fundamentalmente carneros, y de otros productos de importancia menor, como pieles o quesos, fueron sensiblemente inferiores ${ }^{47}$.

\section{LA EVOLUCIÓN DEL MERCADO LANERO Y SU INCIDENCIA SOBRE EL DESA- RROLLO DE LA ACTIVIDAD GANADERA TRASHUMANTE}

La falta de documentación de los siglos XIII y XIV que, como hemos visto, impide reconstruir en detalle los procesos de despegue de la trashumancia y consolidación institucional de la Mesta, resulta igualmente limitadora a la hora

46 Pruebas de que la lana del ganado de raza merina que, por alguna razón, no había trashumado en un determinado ejercicio se cotizaba a precios sensiblemente más bajos, en DiAGO HeRnANDO, Máximo: «El mercado lanero en la región soriana durante los siglos XVI y XVII: Tipología y destino de las lanas», Celtiberia, 96 (2002), pp. 58-9.

47 Aunque las proporciones pudieron variar sensiblemente según los tipos de explotaciones, por regla general los ganaderos trashumantes obtuvieron al menos el $60 \%$ del total de los ingresos de su explotación ganadera de la venta de lanas y añinos. 
de abordar el análisis del funcionamiento del mercado lanero en esta misma época. En efecto, sigue resultando una verdadera incógnita cuál era el destino de las lanas que producían los ganados propiedad de los ganaderos trashumantes sorianos en estos siglos. Sólo tenemos constancia de que en la segunda mitad del siglo XIV, y con más contundencia en sus últimas décadas, los mercaderes italianos que se interesaron por la adquisición de lanas finas en las comarcas serranas de los reinos de Aragón y Valencia, también traspasaron la línea fronteriza y efectuaron compras a los ganaderos de las comarcas de Molina y Cuenca ${ }^{48}$, a donde igualmente acudieron entonces a proveerse de este producto vecinos de la ciudad de Valencia ${ }^{49}$, a veces para proceder a revenderlo a su vez a mercaderes italianos ${ }^{50}$. Pero, por el contrario, no disponemos de ninguna noticia significativa correspondiente a ese siglo sobre adquisiciones de lanas de la región soriana por italianos, y ni siquiera de exportaciones de este tipo de lanas hacia el territorio de la Corona de Aragón, en el que entonces tuvo lugar un notable desarrollo de la actividad de fabricación de paños. La primera referencia documental que hemos localizado sobre una operación de exportación de lanas de la comarca soriana hacia la Corona de Aragón de cierta envergadura data de 1403, año en que durante el mes de agosto el mercader de origen barcelonés asentado en Zaragoza, Ramón Ça Rovira, adquirió una partida de lanas en la comarca de Medinaceli, que luego tuvo dificultades para pasar a Aragón a raíz de la prohibición que el rey Martín I impuso a sus súbditos de comerciar con el reino de Castilla ${ }^{51}$. De no haberse planteado este problema es seguro que no habríamos tenido noticia de tal operación. Y esta constatación nos debe llevar a ser en extremo precavidos a la hora de extraer conclusiones sobre períodos mal documentados, basadas exclusivamente en la mera percepción de la falta de noticias, pues ésta en absoluto constituye indicio suficiente para demostrar la inexistencia de un determinado fenómeno.

En cualquier caso algunos otros indicios apuntan también a presumir que las exportaciones de lanas sorianas hacia la Corona de Aragón no alcanzaron un desarrollo notable durante el siglo XIV. Y entre ellos podemos destacar el hecho de que en los registros del pago del impuesto de la quema en la tabla de Zaragoza

48 Vid. MELIS, Federigo: «La lana della Spagna mediterranea e della Barberia occidentale nei secoli XIV-XV», La lana come materia prima, Florencia, 1974, pp. 242-251.

49 Noticia sobre la compra en Tragacete hacia 1381 por Miguel Quartero, vecino de Valencia, de lana merina que hacía llevar a Valencia en nueve acémilas, y que le fue robada en término de Cañete por el mayordomo de Juan Martínez de Luna, en ACA, C, reg. 1838-7. Se indica que por sentencia de los oficiales de la justicia castellana del año 1381 Juan Martínez de Luna fue obligado a devolver a Miguel Quartero las lanas o en su lugar pagarle $28.630 \mathrm{mrs}$.

50 Vid. IGUAL LUIS, David: Valencia e Italia en el siglo XV. Rutas, mercados y bombres de negocios en el espacio económico del Mediterráneo occidental, Castellón, 1998, p, 103. Informa este autor que en abril de 1380 los genoveses Battista Riso y Francesco Quarç compraron en Valencia 1.900 arrobas de lana de las comarcas de Cuenca, Moya, Utiel y Requena a diversos artesanos y nobles valencianos.

51 ACA, C, reg. 2140-133, Valencia, 2-VI-1404. 
en los meses de mayo, junio, julio y agosto de 1386 no figuran apenas referencias a entradas de lanas de Castilla en Aragón, a pesar de que abundan las noticias sobre operaciones comerciales realizadas por vecinos de Yanguas, jurisdicción en la que la producción lanera debía ser entonces importante ${ }^{52}$.

Si la falta de una fuerte demanda exterior de lanas fue compensada en los siglos XIII y XIV por una vigorosa demanda interior de este producto es algo que, desafortunadamente, tampoco nos permite responder con seguridad la documentación disponible. Algunos autores como Rodríguez Picavea, refiriéndose al conjunto del reino de Castilla, se sienten inclinados a presumir que así fue, al apuntar la hipótesis de que el desarrollo de la ganadería, y en especial de la trashumante, en la época anterior al inicio de las exportaciones masivas de lana a Flandes, pudo deberse al aumento de la demanda de lana por parte de la primitiva industria castellana ${ }^{53}$. Pero lo cierto es que con las informaciones hoy por hoy disponibles dicha hipótesis resulta muy difícil de verificar, e incluso se pueden aducir poderosos argumentos para contradecirla, pues, por ejemplo, un vigoroso desarrollo de la actividad de fabricación de paños de calidad en Castilla durante el siglo XIV resulta difícil de conciliar con la bien constatada realidad de entrada masiva en esta misma época de tejidos a territorio castellano a través tanto de los puertos del Cantábrico como de la frontera terrestre con la Corona de Aragón ${ }^{54}$.

Entendemos, por tanto, que durante los siglos XIII y XIV la existencia de una fuerte demanda de lanas no pudo ser el motor principal que propiciase el auge de la ganadería trashumante en las sierras sorianas. Por el contrario nos sentimos inclinados a pensar que entonces esta actividad se desarrolló en gran medida al margen de los impulsos del mercado en general, y del lanero en particular, debido a que quienes la practicaron serían en su mayor parte pequeños propietarios que se desplazaban en los inviernos a los pastizales del sur apremiados por la imposibilidad de mantener sus rebaños en las sierras por las inclemencias del tiempo. Estos modestos ganaderos no actuarían entonces movidos por el afán de obtener elevados beneficios de la explotación de sus rebaños, sino más bien por el simple apremio de asegurar la subsistencia de sus familias en una tierra montañosa que no facilitaba la tarea, por el escaso rendimiento que en ella ofrecía el cultivo del cereal o de la vid. Pero, al verse forzados a bus-

52 Vid. Diago Hernando, Máximo: «Introducción al estudio del comercio entre las Coronas de Aragón y Castilla durante el siglo XIV: Las mercancías objeto de intercambio», En la España Medieval, 24 (2001), pp. 76 y ss. Entre los numerosos vecinos de Yanguas que entraron con mercancías a Aragón entre mayo y agosto de 1386, sólo uno metió lana, y además en muy pequeña cantidad, tres arrobas. Por contra muchos de ellos síllevaron a vender queso.

53 Rodríguez-Picavea Matilla, Enrique: «La ganadería en la Castilla Medieval. Una revisión historiográfica», Medievalismo, 8 (1998), pp. 111-152, en especial p. 133.

54 Sobre esta cuestión Vid. Diago Hernando, Máximo: «El comercio de tejidos a través de la frontera terrestre entre las coronas de Castilla y Aragón en el siglo XIV», Studia Historica. Historia Medieval, 15 (1997), pp. 171-207.

Hispania, LXIV/3, núm. 218 (2004) 1045-1078 
car alimento para sus ganados en regiones muy alejadas de la suya de residencia, éstos por necesidad tuvieron que incorporarse, aún a su pesar, a una economía mucho más mercantilizada que aquélla en que se desenvolvían sus paisanos que compaginaban el cultivo de la tierra con la cría de unas pocas cabezas de ganado ovino en régimen estante. Precisaban, en efecto, disponer de dinero para pagar los arrendamientos de dehesas en invierno, y para atender los cuantiosos gastos que generaban los desplazamientos a dichas dehesas. Y este dinero debían obtenerlo de la comercialización de los productos generados por su explotación ganadera, entre los que, además de las lanas, estaban los carneros, las ovejas viejas, las pieles de ganados muertos, o los quesos.

Por consiguiente, aunque en su origen la trashumancia en las tierras sorianas comenzó siendo una actividad que, por razón de los móviles de quienes las practicaban, se encuadraba en el marco de la economía de subsistencia, desde el primer momento debió integrarse en mayor medida que otras actividades económicas en la economía de mercado. Ahora bien, entendemos que en sus primeras fases no lo hizo de la misma forma que en el período "clásico" que abarca desde comienzos del siglo XV hasta comienzos del siglo XIX, durante el que persistió, aunque con altibajos, una fuerte demanda exterior de lanas finas. Por el contrario, en la primera fase del desarrollo de la trashumancia en las sierras sorianas los ingresos obtenidos de la venta de lanas no pudieron tener la importancia que más tarde alcanzaron como principal sustento financiero de las explotaciones ganaderas. Quizás entonces las ventas de ganado para carne, tanto de carneros como de ovejas viejas, fueron las que mayores ingresos proporcionaron, a la vez que otras partidas que en momentos posteriores resultaron insignificantes, como, por ejemplo, las ventas de quesos, realizarían también una aportación nada desdeñable ${ }^{55}$. Pero, a falta de informaciones más precisas en la escasa documentación conservada, resulta imposible demostrar el grado de veracidad de estas hipótesis, basadas exclusivamente en meras deducciones.

En cualquier caso entendemos que este panorama se vendría a alterar de forma radical a partir de las primeras décadas del siglo XV, cuando la demanda de lanas castellanas en el mercado flamenco se disparó, por efecto del desarrollo de las new_draperies y del hundimiento de las exportaciones inglesas en este mercado ${ }^{56}, \mathrm{y}$ además surgieron otros importantes centros de demanda para

ss Nos ha llamado la atención la importancia que en torno a 1386 tuvo la exportación de quesos desde la región soriana, y muy en particular desde Yanguas, hacia el reino de Aragón. Vid. Diago Hernando, Máximo: “Introducción al estudio...», pp. 78-9. Otra noticia que confirma la importancia del comercio del queso para los vecinos de Yanguas en la primera mitad del siglo XIV en Rubio Semper, Agustín: Fuentes Medievales Sorianas. Agreda II, Soria, Diputación Provincial, 2001, doc. $\mathrm{n}^{\circ}$. 167, Ágreda, 23-VIII-1340. Un vecino de Las Aldehuelas, aldea de Yanguas, denunció que cuando se encontraba en casa de un tabernero en Trévago, aldea de Ágreda, le robaron un rocín que llevaba cargado con cuatro arrobas de queso.

56 Sobre estos procesos de transformación de la industria pañera flamenca vid. MUNRO, J.H.: Wool, cloth and gold. The struggle for bullion in Anglo-Burgundian Trade 1340-1478, Bruselas-Toronto, 
estas lanas en otras regiones ribereñas del Atlántico, como Normandía o Bretaña. Los efectos que sobre una región podía producir el repentino desarrollo de una fuerte demanda de lanas en el mercado internacional ya fueron puestos de manifiesto por el profesor Sesma Muñoz en un sugerente artículo dedicado al estudio de la incidencia que la demanda de lanas para su exportación a Italia tuvo sobre ciertos lugares del sur de Aragón durante el siglo XIV ${ }^{57}$. Y entendemos que una situación parecida a la que se vivió en las comarcas serranas de los reinos de Aragón y Valencia, y en menor medida también en las de Molina y Cuenca, en la Corona de Castilla, durante la segunda mitad del siglo XIV, pudo reproducirse en las sierras sorianas y cameranas unas pocas décadas más tarde, a comienzos del siglo XV, a raíz de la apertura de los mercados europeos del Atlántico, a los que ciertamente ya se habían estado destinando lanas desde Castilla con anterioridad, pero en un volumen poco considerable.

La aparición de esta fuerte demanda de lanas finas, producidas por el ganado ovino de raza merina que recorría largas distancias cada año, debió actuar como un poderoso incentivo para que muchos individuos emprendedores en la región soriana se decidiesen a realizar importantes inversiones en la actividad ganadera trashumante, por las buenas perspectivas que ofrecía de obtener saneados beneficios de la comercialización de las lanas producidas por los rebaños, para las cuales en momentos anteriores debió resultar mucho más difícil encontrar compradores dispuestos a pagar un precio remunerador. Y como consecuencia, a partir de entonces, se debió incrementar de forma apreciable el número de personas interesadas en la posesión de cabañas de ganado trashumante por motivos relacionados con el afán de obtener beneficios mediante inversiones con cierto carácter especulativo, y no ya sólo exclusivamente con la necesidad de asegurarse la subsistencia en medios geográficos poco fértiles.

Muchas de estas personas surgieron de entre las numerosas familias asentadas en las comarcas serranas que venían practicando desde hacía mucho tiempo la trashumancia con pequeños rebaños, y habían adquirido como consecuencia una valiosa experiencia en esta forma de explotación ganadera. Pero, al mismo tiempo, también hubo otras muchas procedentes de grupos sociales que hasta entonces nada habían tenido que ver con la ganadería trashumante, las cuales, si pasaron a interesarse por ella, fue por haber tomado conciencia de las buenas oportunidades que el incremento de la demanda lanera ofrecía para obtener saneados beneficios de esta actividad.

1972. Y también VAN DER WeE, H.: «Industrial Dynamics and the process of Urbanization and De-Urbanization in the Low Countries from the Late Middle Ages to the Eighteenth Century. A synthesis", en VAN DER WEE, H. (Ed.), The rise and decline of urban industries in Italy and the Low Countries (Late Middle Ages-Early Modern Times), Lovaina, 1988, pp. 326-336.

57 SESMA MUÑOZ, J.A.: «Producción para el mercado, comercio y desarrollo mercantil en espacios interiores (1250-1350): el modelo del sur de Aragón", Europa en los umbrales de la crisis (12501350). XXI Semana de Estudios Medievales. Estella 94, Pamplona, 1995, pp. 205-46.

Hispania, LXIV/3, núm. 218 (2004) 1045-1078 
En efecto, el análisis de la escasa información disponible para la identificación de las principales familias ganaderas trashumantes de la cuadrilla mesteña soriana en el siglo XV nos permite comprobar que entre ellas hubo, por un lado, varias que hundían sus raíces en las aldeas serranas en las que desde hacía siglos se venía practicando la trashumancia, mientras que, por otro lado, también hubo bastantes «advenedizas", procedentes de ambientes totalmente alejados de esta actividad, que, sin embargo, volcaron de lleno en ella sus inversiones en el transcurso del siglo XV, animadas por las buenas perspectivas de negocio que ofrecía. En el primer grupo se podrían incluir la mayoría de las familias a las que hemos hecho alusión en epígrafes anteriores, por lo cual no vamos a dedicar ahora más atención a su identificación, para centrarnos por el contrario en el segundo grupo de familias, que trataremos de caracterizar mediante la selección de algunos ejemplos paradigmáticos de individuos procedentes de otras regiones del reino de Castilla y de fuera de él, que fijaron su residencia en la región soriana en el transcurso del siglo XV, y muy pronto se incorporaron al grupo de los mayores propietarios de rebaños de ganado trashumante de esta región, en el que sus descendientes permanecieron en la mayor parte de los casos hasta el propio siglo XIX.

Un ejemplo sobresaliente que hemos conseguido reconstruir con cierto detalle nos lo proporciona el hidalgo de origen gallego Juan López de Río, quien, procedente de un pequeño lugar del obispado de Mondoñedo, se instaló en Yanguas a mediados del siglo XV, tras haber entrado al servicio del señor de la villa, Juan Ramírez de Arellano, que le nombró alcaide de su fortaleza. Gracias a su matrimonio con una doncella de la familia de los Malo, destacada propietaria ganadera de Yanguas ${ }^{58}$, se haría con la propiedad de sus primeros ganados merinos, que más adelante sus hijos y nietos consiguieron multiplicar, a la vez que ponían tanto esmero en mejorar la raza, que finalmente su cabaña, la de los señores Ríos, consiguió consolidarse en el transcurso del siglo XVI como la productora de lana de mejor reputación en todo el ámbito abarcado por el partido mesteño de Soria, que por esta razón se pagaba regularmente a unos precios superiores a los abonados por el resto de lanas «sorianas» 59 .

Una trayectoria en muchos aspectos parecida a la de Juan López de Río presenta Pedro García de Cereceda, hidalgo originario de la comarca de Laredo, quien, siendo todavía mozo soltero, vino a servir a mediados del siglo XV a Juan Ramírez de Arellano, que le puso al cargo de su casa y hacienda, por lo cual también fue conocido con el nombre de Pedro García de la Plata. Y al servicio de los Arellano continuaron haciendo su fortuna sus descendientes, de

58 Según los registros del pago del peaje en el puente de Capilla, en octubre de 1428 pasaron por allí 10.886 cabezas de ganado ovino pertenecientes a Juan Malo, vecino de Yanguas.

59 Vid. Diago Hernando, Máximo: «Estrategias de ascenso social en la Castilla del siglo XVI. El ejemplo de la familia Río en Soria», Historia Social, 49 (2004), pp. 3-27. Y "Los caballeros ganaderos de Soria y su Tierra durante los siglos XVI y XVII. Contribución al estudio del grupo de los grandes señores de ganados mesteños», Celtiberia, 97 (2003), pp. 127-72.

Hispania, LXIV/3, núm. 218 (2004) 1045-1078 
forma que su hijo Juan de Cereceda fue designado para los cargos de maestresala y alcaide de Yanguas por el primer conde de Aguilar, Don Alonso de Arellano, y dos de los hijos de éste continuaron sirviendo a esta casa, como contador y maestresala respectivamente ${ }^{60}$. Pero, al igual que los Río, los Cereceda, una vez instalados en Yanguas, no se limitaron a vivir de los sueldos recibidos de la casa de Arellano en compensación por sus servicios, sino que muy pronto comenzaron también a invertir en la explotación de rebaños de ganado ovino trashumante, y lo hicieron con tal fortuna que descendientes suyos continuaban figurando entre los principales propietarios ganaderos de la Tierra de Yanguas en el siglo XVIII' ${ }^{61}$.

Un tercer ejemplo de familia de origen foráneo que se instaló en Yanguas hacia mediados del siglo XV por haber entrado al servicio de los Arellano, y que muy pronto se incorporó al grupo de las más reputadas propietarias de ganado trashumante del partido mesteño soriano es la de los Fuenmayor, originaria, al parecer, de Baeza ${ }^{62}$. Y, fuera de Yanguas, encontramos también testimonios semejantes, por ejemplo en la vecina villa de San Pedro Manrique, donde a fines del siglo XV se instalaron los primeros miembros de la familia Gante, originaria de esta ciudad de los Países Bajos, que comenzaron estando al servicio del duque de Nájera, señor de esta villa serrana, aunque muy pronto se alzaron a la posición de principales señores de ganados trashumantes de dicha jurisdicción, que mantuvieron hasta el fin del Antiguo Régimen.

Los ejemplos aducidos, todos ellos referentes a hidalgos que llegaron a la región soriana para servir a miembros de la alta nobleza, y que se instalaron en lugares de señorío, podrían inducir a pensar que, en línea con la hipótesis defendida por la profesora Asenjo, los territorios de señorío ofrecían en el siglo $\mathrm{XV}$ en la sierra de Soria mayores posibilidades para sacar adelante con éxito explotaciones ganaderas trashumantes. Pero lo cierto es que también en los territorios realengos se avecindaron entonces individuos de origen foráneo que rápidamente prosperaron gracias a su dedicación a la actividad ganadera trashumante. Un testimonio temprano nos lo proporciona, por ejemplo, la familia Calderón, que se instaló en la aldea serrana de Gallinero en el transcurso de la primera mitad del siglo XV, procedente, al parecer, de Villoslada de Cameros, según ya hemos referido con anterioridad. Pero para fechas algo más tardías disponemos de otros ejemplos en que los protagonistas son personas procedentes de lugares mucho más distantes.

$60 \mathrm{AChV}, \mathrm{Hijosdalgo,} \mathrm{53-2.} \mathrm{Se} \mathrm{informa} \mathrm{que} \mathrm{el} \mathrm{valle} \mathrm{de} \mathrm{Cereceda,} \mathrm{de} \mathrm{donde} \mathrm{era} \mathrm{originario} \mathrm{Pe-}$ dro García de Cereceda, pertenecía a la jurisdicción de Laredo, y también se hace referencia a la iglesia de San Martín de Cereceda.

61 Vid. AlCALDE JimÉnEZ J.M ${ }^{\mathrm{a}}$, art. cit. pp. 78 y ss.

62 Vid. Diago Hernando, Máximo: Soria en la Baja Edad Media... pp. 153-4, y 188. En el transcurso del siglo XVI los ganaderos de apellido Fuenmayor proliferaron por toda la región soriana, no sólo en Yanguas, sino también en la propia Soria y en Ágreda. 
Es el caso de los hermanos Juan y Martín García de Sevilla, quienes se instalaron en la aldea pinariega de Vinuesa procedentes de esta ciudad andaluza en fecha no determinada por las fuentes documentales consultadas, pero que habría que situar probablemente en las últimas décadas del siglo XV. Eran pecheros, pero recibieron privilegio de hidalguía del rey Carlos I en 1517, en premio por haber servido con sus personas en el cerco de Pamplona, durante la guerra de conquista de Navarra63. Y sabemos que para entonces se habían convertido en hombres muy ricos, porque así lo manifestó el concejo de Vinuesa, cuando reclamó la suspensión del referido privilegio, alegando el grave perjuicio que causaba a sus vecinos pecheros, debido a la enorme riqueza que acumulaban los dos hermanos, que tenían además cerca de veinte hijos, por la cual les correspondía pechar a ellos dos solos tanto como a la mitad del resto de los vecinos pecheros del lugar ${ }^{64}$. Y no nos cabe duda de que gran parte de esta notable riqueza acumulada la debieron a su actividad como ganaderos trashumantes, a la que continuaron dedicados muchos de sus descendientes durante el resto del siglo XVI, a la vez que realizaban de cuando en cuando algunas incursiones en el mundo del comercio ${ }^{65}$.

Pero, si en el siglo XV tuvieron lugar episodios de avecindamiento de forasteros en Tierra de Soria que pronto hicieron fortuna gracias a la ganadería trashumante, nos atreveríamos a afirmar, a juzgar por las noticias de las que hoy por hoy disponemos, que el proceso se intensificó apreciablemente durante la primera mitad del siglo XVI, cuando tuvo lugar el cambio de residencia a esta jurisdicción de importantes señores de ganados del entorno, entre los que habría que destacar muy en particular a los procedentes de Yanguas ${ }^{66}$.

63 La provisión del rey por la que les hacía merced de la hidalguía estaba fechada en Gante, 5VI-1517, y fue confirmado por carta de privilegio fechada en Madrid, 6-VI-1517. Vid. AHN, Consejos, leg. 25.614. Más adelante el concejo de Vinuesa denunció que este privilegio se había obtenido con falsa relación, pues estos dos hermanos no habían servido en ninguna acción bélica en el reino de Navarra, sino que habían viajado allí para llevar carneros y no como hombres de armas. La denuncia de Vinuesa en AGS, Cámara de Castilla, Memoriales, leg. 151-197, sin fecha. Cita ASENJO GONZÁLEZ, Ma .: Espacio y sociedad... p. 463.

64 AGS, RGS, X-1518, y AHN, Consejos, leg. 25.614. A pesar de las denuncias presentadas por el concejo de Vinuesa, la Chancillería de Valladolid confirmó el privilegio de hidalguía por sentencia definitiva pronunciada en Valladolid, 5-V-1520. Gracias a su notable riqueza Juan García de Sevilla consiguió casar a su hija Inés con Lope Álvarez de Calatañazor, hijo del regidor soriano del mismo nombre. Los capítulos matrimoniales, otorgados en Soria, 5-VII-1537, en AHPS (=Archivo Histórico Provincial de Soria), PN (=Protocolos Notariales), antigua caja 42.

65 Algunas noticias sobre la importancia de los Sevilla como propietarios ganaderos durante el siglo XVI en DiAgo HeRNANDO, Máximo: «Los caballeros ganaderos de Soria y su Tierra...» p. 151. De su dedicación al comercio da testimonio la noticia de la constitución de una compañía dedicada al «trato de lanas y mercaderías», por Bernardino de Sevilla, vecino de Vinuesa, junto con Francisco Sanz Cascante, vecino de Villar del Río, aldea de Yanguas, y el maestro Pedro de La Puente, colegial en el colegio de Lugo de la villa de Alcalá de Henares y vecino de Diustes, también aldea de Yanguas. Vid. AHPS, PN, 72-162-111, El Royo, 20-VIII-1601.

66 Breves referencias a este fenómeno en Diago Hernando, Máximo: Soria en la Baja Edad Media... pp. 142-3, y 155-6.

Hispania, LXIV/3, núm. 218 (2004) 1045-1078 
En cualquier caso, dejando a un lado la cuestión de la redistribución de los ganaderos en el interior del espacio geográfico soriano, lo que nos interesa aquí recalcar es que durante el siglo XV y la primera mitad del siglo XVI el despegue de las exportaciones de lanas finas castellanas a Flandes y otros territorios ribereños del Atlántico, iniciado a comienzos del siglo XV, propició la consolidación en este espacio de un clima favorable para los individuos de talante emprendedor dispuestos a arriesgarse en inversiones con cierto carácter especulativo, que generó una situación muy propicia para la movilidad social, en la que proliferaron los procesos de rápido ascenso de nuevas familias, que debieron en gran medida su fortuna a haber sabido invertir a tiempo y con acierto en una actividad económica en expansión que prometía proporcionar buenos rendimientos económicos.

Esta situación se prolongó aproximadamente hasta mediados del siglo XVI, cuando se produjo la masiva incorporación de las «nuevas familias» ganaderas al grupo oligárquico de la ciudad de Soria, y los señores de ganados de Ágreda se adueñaron de la mayor parte de los nuevos regimientos vitalicios creados en la villa, hasta entonces gobernada por regidores de renovación anual ${ }^{67}$. De este modo las oligarquías de los dos principales concejos de realengo de la región quedaron profundamente renovadas, y pasaron a ofrecer un nuevo perfil caracterizado por el predominio de las familias ganaderas trashumantes, que hasta entonces no había sido tan claro.

Para entonces también quedó en gran medida consolidada la estructura de distribución de la propiedad de la cabaña ganadera trashumante, que estuvo caracterizada por una fuerte polarización, pues un puñado de familias terminó concentrando en sus manos la mayor parte de las cabezas de ganado ovino mantenidas en régimen trashumante en la región soriana ${ }^{68}$. Y la mayor parte de ellas continuaron manteniendo dicha posición de grandes propietarias ganaderas hasta finales del siglo XVIII, dejando muy poco lugar para la renovación del grupo de mayores propietarios, que sólo con cuentagotas fue incorporando nuevos miembros, reclutados preferentemente en el seno del grupo de los mercaderes, los cuales, sin embargo, solían permanecer poco tiempo dedicados a esta actividad y pronto optaban por deshacerse de los rebaños ${ }^{69}$.

Este proceso de concentración de la propiedad del ganado trashumante en manos de unas pocas familias entendemos que fue en gran medida consecuencia de la nueva orientación de acentuado carácter especulativo que tomó la actividad

67 Esta afirmación referente a Ágreda la basamos en indicios, pues de momento todavía no se conoce con detalle el proceso de transformación de la institución concejil que tuvo lugar en esta villa en el transcurso del siglo XVI, por no haberse dedicado ningún estudio a su reconstrucción y análisis.

68 Para la identificación de estas familias Vid. Diago Hernando, Máximo: «Los caballeros ganaderos de Soria y su Tierra...».

69 Sobre esta cuestión Vid. Diago Hernando, Máximo: «Mercaderes propietarios de ganado trashumante en la cuadrilla mesteña soriana en los siglos XVI y XVII», Studia Historica. Historia Moderna (En prensa). 
ganadera trashumante tras producirse el despegue de las exportaciones laneras a través de los puertos del Cantábrico. En efecto, en el marco de intensa mercantilización de esta actividad que la nueva situación generó, las grandes explotaciones operaban con ventajas comparativas respecto a las medianas y pequeñas, y por tanto tendían a imponerse sobre ellas. Y fue por este motivo por el que, paradójicamente, muchas familias campesinas de las comarcas serranas que probablemente venían practicando la trashumancia generación tras generación desde hacía ya varios siglos, terminaron quedando relegadas en este nuevo contexto, en el que la demanda exterior de lanas marcaba las pautas de evolución de la actividad ganadera, a una posición secundaria, de simples comparsas de las familias propietarias de las grandes cabañas. Pero, aunque estas familias sólo controlaban la propiedad de una fracción muy reducida del conjunto de la cabaña trashumante soriana, no cabe duda tampoco de que continuaron representando la principal fuerza de trabajo que aseguró el mantenimiento de toda ella, pues fue en su seno donde los propietarios de las grandes y medianas cabañas reclutaron a los numerosos pastores y mayorales que debían estar al cargo de sus rebaños.

El incremento significativo de la demanda de lanas finas en los mercados ribereños del Atlántico iniciado en las primeras décadas del siglo XV creemos, por tanto, que actuó como un verdadero revulsivo sobre las estructuras económicas, sociales y políticas del ámbito soriano durante un largo período que se prolongó hasta mediados del siglo XVI. Entonces tuvo lugar el proceso de gestación de un nuevo grupo llamado a dominar el escenario sociopolítico soriano hasta el fin del Antiguo Régimen, el de los grandes señores de ganados trashumantes. Y, como hemos tratado de demostrar, éste tuvo una composición muy heterogénea, pues en él se integraron individuos de muy diversas procedencias sociales y geográficas, unidos por un denominador común, el talante emprendedor y la predisposición hacia la inversión especulativa.

En aquel momento la sociedad soriana fue capaz de responder al reto que le planteaba la apertura de unos mercados con grandes posibilidades, optando por invertir de forma masiva en una actividad que, por apremios de origen ecológico, ya se venía practicando a menor escala desde hacía tiempo. Y esta opción contribuyó decisivamente a reforzar su economía durante cerca de cuatro siglos, permitiendo que la contribución al producto interior bruto castellano de esta zona se mantuviese hasta comienzos del siglo XIX en unos niveles aceptables, que después descendieron drásticamente, y ya no se han vuelto a recuperar.

Pero, llegados a este punto, conviene llamar la atención sobre el hecho de que, ante el reto planteado por el incremento de la demanda de lanas, no se respondió de forma semejante en todos los ámbitos serranos del reino de Castilla, que eran en principio los que mejor podían responder a esa demanda, por ofrecer condiciones óptimas para la cría de ganado ovino de raza merina en régimen trashumante. Desde este punto de vista, se ha de resaltar, en efecto, el hecho de que ni en la montaña leonesa, ni en ningún otro de los territorios serranos de la Cordillera Cantábrica, tuvo lugar en los siglos XV y XVI, ni tampoco en siglos posteriores, un fenómeno de desarrollo de la ganadería tras-

Hispania, LXIV/3, núm. 218 (2004) 1045-1078 
humante protagonizado por la población autóctona semejante al que hemos detectado en Soria. Por el contrario, los magníficos pastos que ofrecen los puertos de la provincia de León en el verano para alimento del ganado ovino fueron aprovechados en su práctica totalidad durante los siglos de la Edad Moderna, y con mayor intensidad a partir de finales del siglo XVI, por ganaderos forasteros, vecinos de Segovia, Madrid y otras ciudades y villas de la submeseta sur, mientras que la población autóctona se limitó a ofrecer su fuerza de trabajo a estos últimos, que los contrataron como sus mayorales y pastores ${ }^{70}$.

En el estado actual de las investigaciones ni siquiera sabemos si ya durante el siglo XV y la primera mitad del siglo XVI los pastos de verano de las montañas de León fueron objeto de un intensivo aprovechamiento, o por el contrario el número de ganados trashumantes que acudieron a dicho ámbito en la estación estival sólo comenzó a ser importante a partir de finales del siglo XVI, incrementándose luego de forma sostenida durante los siglos XVII y XVIII conforme los vecinos de Madrid y de otras ciudades de la mitad sur peninsular iban reuniendo en sus manos cada vez mayor número de cabezas de ganado ovino merino. Pero, en cualquier caso, está fuera de duda que tampoco antes de que llegaran de forma masiva estos señores de ganados foráneos proliferaron en la región ganaderos trashumantes autóctonos de cierto relieve, pues no resulta posible encontrar mención alguna a ellos en los libros de actas de la Mesta, conservados a partir de 1499 , ya que ninguno de los ganaderos que aparecen integrados en la llamada cuadrilla de León eran vecinos de lugares de la actual provincia leonesa.

\section{ConClusión.}

En función de cuanto llevamos dicho consideramos justificado concluir, por tanto, que las sierras sorianas se contaron entre las comarcas del reino de Castilla pioneras en la práctica de la trashumancia de largo recorrido, y que los ganaderos allí asentados debieron desempeñar un papel de primera fila en la puesta en funcionamiento de la institución mesteña, para proteger sus intereses frente a los propietarios de los pastos de invernadero y cuantos pudiesen dificultar las migraciones de sus ganados en las largas rutas que tenían que recorrer. Y este protagonismo inicial es el que explicaría los privilegios relativos al orden de precedencia que los miembros del partido soriano tuvieron reconocidos en el seno de la Mesta hasta su disolución.

70 No se dispone de estudios monográficos dedicados al análisis de la ganadería trashumante en las montañas de León para fechas anteriores al siglo XVIII. Un trabajo centrado preferentemente en el período que va de mediados del siglo XVIII al siglo XX es el de GómÉz SAL, Antonio y RoDRíGuEZ PASCUAL, Manuel: Cuadernos de la Trashumancia. 3. Montañas de León, ICONA, 1992. Sobre la afluencia de ganados segovianos a los puertos de León Vid. PÉREZ MOREDA, Vicente: «La transhumance estivale des mérinos de Segovie: Le pleito de la Montaña», Mélanges de la Casa de Velázquez, 14 (1978), pp. 285-312.

Hispania, LXIV/3, núm. 218 (2004) 1045-1078 
En cualquier caso esta temprana orientación hacia la práctica de la trashumancia se daría tanto en los territorios de señorío como en los de realengo de la sierra soriana, pues venía propiciada por factores de carácter ecológico más que por otros relacionados con el régimen de aprovechamiento de pastos impuesto por uno u otro modelo de gobierno. La falta de noticias sobre comercialización a gran escala de lanas sorianas en los siglos XIII y XIV invita a presumir, no obstante, que, en estas primeras fases, la ganadería trashumante no se desarrolló en la referida región en respuesta a los estímulos del mercado, sino que, salvando algunos casos excepcionales de grandes propietarios que la escasez de fuentes documentales apenas permite identificar, fue una actividad practicada prioritariamente por pequeños propietarios campesinos que se movían en el horizonte de la economía de subsistencia, y sólo recurrían al mercado forzados por la necesidad de disponer de dinero para asegurar el funcionamiento de su explotación ganadera.

El progresivo incremento de la demanda de lanas en el mercado, y muy en especial en el exterior, iría alterando progresivamente esta situación, no pudiéndose descartar que ya en el transcurso del siglo XIV se produjesen cambios, si bien la carencia de fuentes de información impide de momento precisarlo. Pero lo que sí está fuera de duda es que durante la primera mitad del siglo XV estos cambios ya sí alcanzaron cierta intensidad, que fue en aumento con el transcurso del tiempo, hasta dar como resultado la consolidación de una nueva situación, caracterizada por la asunción de un marcado carácter especulativo por parte de la actividad ganadera trashumante, que terminó quedando bajo el control de un puñado de familias de grandes propietarios, a los que servían una legión de pastores y mayorales avecindados en su práctica totalidad en las aldeas serranas.

Desde este punto de vista, sospechamos, por tanto, que la región soriana evolucionó con cierto retraso con respecto a otras comarcas serranas de la Corona de Castilla en que se practicó la trashumancia, tales como las de Cuenca y Molina, en las que los efectos del incremento de la demanda lanera en el mercado internacional ya se hicieron sentir de forma apreciable durante la segunda mitad del siglo XIV. De hecho todavía a principios del siglo XVI la lana procedente de estas comarcas seguía gozando de mayor estimación en los mercados, y conseguía por ello precios más elevados que la de las sierras sorianas, y al parecer también que la de las sierras segovianas. Pero esta situación cambió de forma radical en el transcurso de este siglo, hasta el punto de que ya a comienzos del siglo XVII las lanas de Cuenca y Molina se cotizaban a precios muy inferiores a los alcanzados por las de Segovia, que eran las más caras, sobre todo en su variante llamada «leonesa», y por las de Soria. Y esta alteración en la relación de precios entendemos que nos proporciona el mejor indicio de la naturaleza de los cambios que en los siglos previos habían tenido lugar, que propiciaron la transformación de las explotaciones ganaderas trashumantes sorianas en verdaderas «empresas» con orientación decididamente especulativa, en productoras de lana de primera calidad para el mercado internacional. 